Elsevier required licence: (c) 2017. This manuscript version is made available under the CC-BY-NC-ND 4.0 license http://creativecommons.org/licenses/by-nc-nd/4.0/ 


\title{
Single and Dual Stage Closed-Loop Pressure Retarded Osmosis for Power Generation: Feasibility and Performance
}

\author{
*Ali Altaee ${ }^{1}$, Patricia Palenzuela², Guillermo Zaragoza ${ }^{2}$, Adnan Alhathal AlAnezi ${ }^{3}$ \\ ${ }^{1}$ School of Civil and Environmental Engineering, University of Technology Sydney, \\ Sydney, NSW 2007, Australia. ${ }^{2}$ CIEMAT, Plataforma Solar de Almería, Ctra. de Senés \\ s/n, 04200 Tabernas, Almería, Spain. ${ }^{3}$ Department of Chemical Engineering \\ Technology, College of Technological Studies, The Public Authority for Applied \\ Education and Training (PAAET), P.O. Box 117, Sabah Alsalem 44010, Kuwait
}

\begin{abstract}
This work proposes an analysis of conventional (single stage) and dual stage Closed-Loop Pressure Retarded Osmosis (CLPRO) for power generation from a salinity gradient resource. Model calculations were performed taking into account the influence of operating parameters such as the draw solution concentration, membrane area, and draw solution pressure on the performance of the CLPRO process. Modeling results showed that the dual stage CLPRO process outperformed the conventional CLPRO process and power generation increased $18 \%$ by adding a second stage of PRO membrane. Multi-Effect Distillation (MED) was selected for the regeneration of the draw solution taking advantage of an available source of waste heat energy. The performance of MED process has been assessed by investigating two key parameters: the specific thermal consumption and the specific heat transfer area. The model calculations showed that the power generation by the single and dual stage CLPRO was higher than the electrical power consumption by the MED plant. In the case of the power generation obtained by the dual stage CLPRO, it was 95\% higher than the electrical power consumption by the MED plant, proving the possibility of using low-grade heat for producing electricity from a salinity gradient resource.
\end{abstract}

Keywords: Pressure Retarded Osmosis, Dual Stage Pressure Retarded Osmosis, Osmotic Power Plant, Thermal Regeneration, Dual Stage PRO Optimization

\section{Introduction:}

The application of salinity gradient resource for power generation has been widely recognized as an efficient and low cost approach of renewable energy [18]. The most common techniques for power generation from a salinity gradient are the Pressure Retarded Osmosis (PRO) and Reverse Electrodialysis (RED) [1-14]. PRO process has attracted a lot of attention for harvesting the energy of salinity gradient because of its high efficiency and flexibility to be combined with desalination technologies such as Reverse Osmosis (RO) [6, 7, 10, 12]. 
Experimental works have demonstrated the feasibility of PRO process application in a small commercial power plant [15]. Closed-Loop PRO (CLPRO) has also been proposed for power generation as a heat engine but only few studies have been published in this field $[8,16,17]$. Previous studies focused on the performance of the PRO part and no data have been provided about the performance of the entire CLPRO-thermal system. Furthermore, no studies have been published yet on the potential of using closed-loop dual stage PRO process for power generation.

PRO process uses osmotic energy as the driving force for power generation. A high osmotic pressure draw solution (DS) is fed at one side of a semipermeable membrane whereas a low osmotic pressure feed solution (FS) is pumped into the opposite side of the membrane to create an osmotic pressure gradient, which induces fresh water transportation towards the DS [Figure 1]. Fresh water transport across the membrane will convert the chemical potential into a hydraulic energy. Finally, the diluted DS is depressurized by a hydroturbine for power generation. Although PRO was suggested in the seventies [18], it did not receive considerable attention due to the technical limitations associated with the membrane permeability and rejection rate [14-19]. Recent developments in the membrane manufacturing industries have brought back the strong interest in the PRO concept for power generation [19-20]. New PRO membranes have high water permeability and rejection rate, which revolutionized the PRO and enhanced its performance [18]. Pilot plant tests using Toyobo membrane demonstrated high power density of $7.7 \mathrm{~W} / \mathrm{m}^{2}$ [15], which was more than the theoretical recommended value $\left(5 \mathrm{~W} / \mathrm{m}^{2}\right)$ for an economic PRO process [20]. Furthermore, previous studies have achieved power density larger than $10 \mathrm{~W} / \mathrm{m}^{2}$ using a laboratory fabricated PRO membrane and 6\%-0.06\% salinity gradient resource [19].

One of the operating challenges for the PRO process is the selection of a suitable salinity gradient resource to create a sufficient driving force across the PRO membrane. A number of salinity gradients have been suggested by coupling seawater or brine from a Reverse Osmosis (RO) process with wastewater effluent or fresh water [14, 15, 20-22]. It is preferable applying high concentration DS to obtain high membrane flux across the PRO membrane. Previous works showed that Concentration Polarization (CP) across the membrane increases with increasing permeation flow and reducing the efficiency of PRO process [23-25]. CP is divided into dilutive and concentrative; dilutive CP occurs usually on the DS side whereas the concentrative CP occurs on the FS. However, using deionized water negates the effect of concentrative $\mathrm{CP}$ and improves the performance of PRO [23].

Closed-Loop PRO (CLPRO) has been proposed as a means for salinity gradient energy capture when no natural streams are available [25]. The salinity gradient resource in the CLPRO process consists of a high osmotic pressure DS and deionized/low concentration FS [Figure 1A]. In this case, the diluted DS goes to a 
regeneration unit after leaving the hydroturbine system [24]. The concentrated 92 DS and fresh water are the products of the regeneration process which are 93 recycled back to the PRO membrane. Due to the high purity of draw and feed solutions, CLPRO has the advantage of reducing the PRO membrane fouling, and allowing the recycling and reuse of the salinity gradient resource [8]. designed by changing the concentration and hydraulic pressure of DS. Figure 1 shows a schematic diagram of single and dual stage CLRPO plants which are operated in a continuous mode. Practically, the feed solution would be contaminated due to $\mathrm{NaCl}$ back diffusion from the DS. Therefore, the feed solution needs purging over time whereas the concentration of DS can be adjusted by adding the $\mathrm{NaCl}$ stock solution.

Some recent published studies have analyzed the performance of conventional PRO process in the CLPRO process [25-28]. Dual stage PRO (DSPRO) process has shown higher power generation potential than conventional PRO [27, 29]. The process has the potential of increasing the energy yield of salinity gradient and reducing the membrane fouling [27, 29,32], but no studies have investigated its performance in a CLPRO system so far. The present study was focused on analyzing the performance of a dual stage CLPRO process and on demonstrating its advantages over the single stage CLPRO process. Also, the regeneration of the draw solution by a thermal desalination process such as Multi-effect distillation (MED) has been investigated. For this purpose, the use of a free source of waste heat has been considered and a certain specific electricity consumption of the MED system was assumed in the calculation of the net power generation of the PRO process. A pre-developed computer model was applied for optimizing the concentration and osmotic pressure of the DS, taking into account the effect of some key operating parameters such as the draw solution pressure, flow rates, and membrane area on the performance of the PRO process. The PRO model was calibrated using experimental data [12] and the PRO data outputs were taken as the inputs to the MED regeneration process for energy calculations purposes. For the regeneration part, a computer model was used in order to analyze the performance of MED system under several operating conditions. The results define a baseline for the potential and feasibility of CLPRO for power production. 


\section{A: Single Stage}

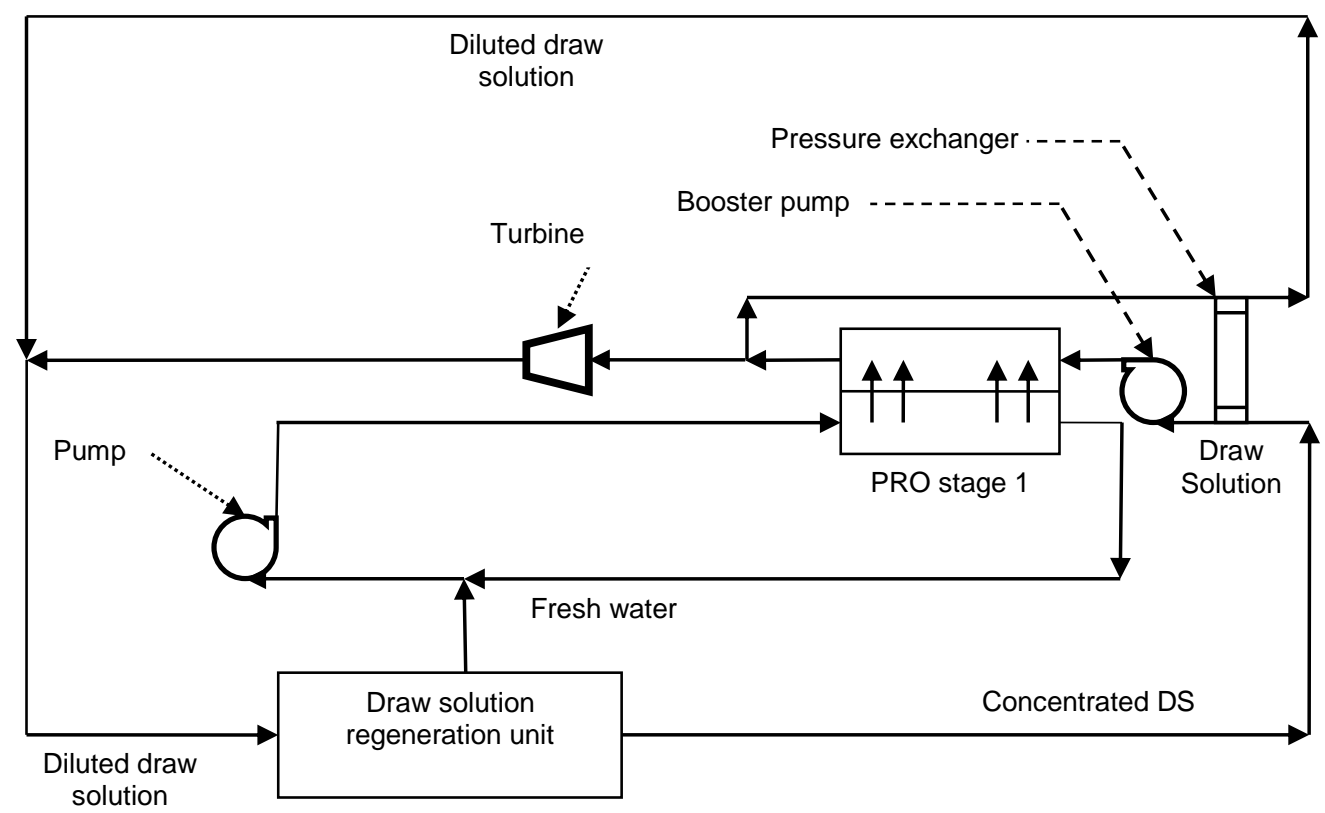

\section{B: Dual Stage}

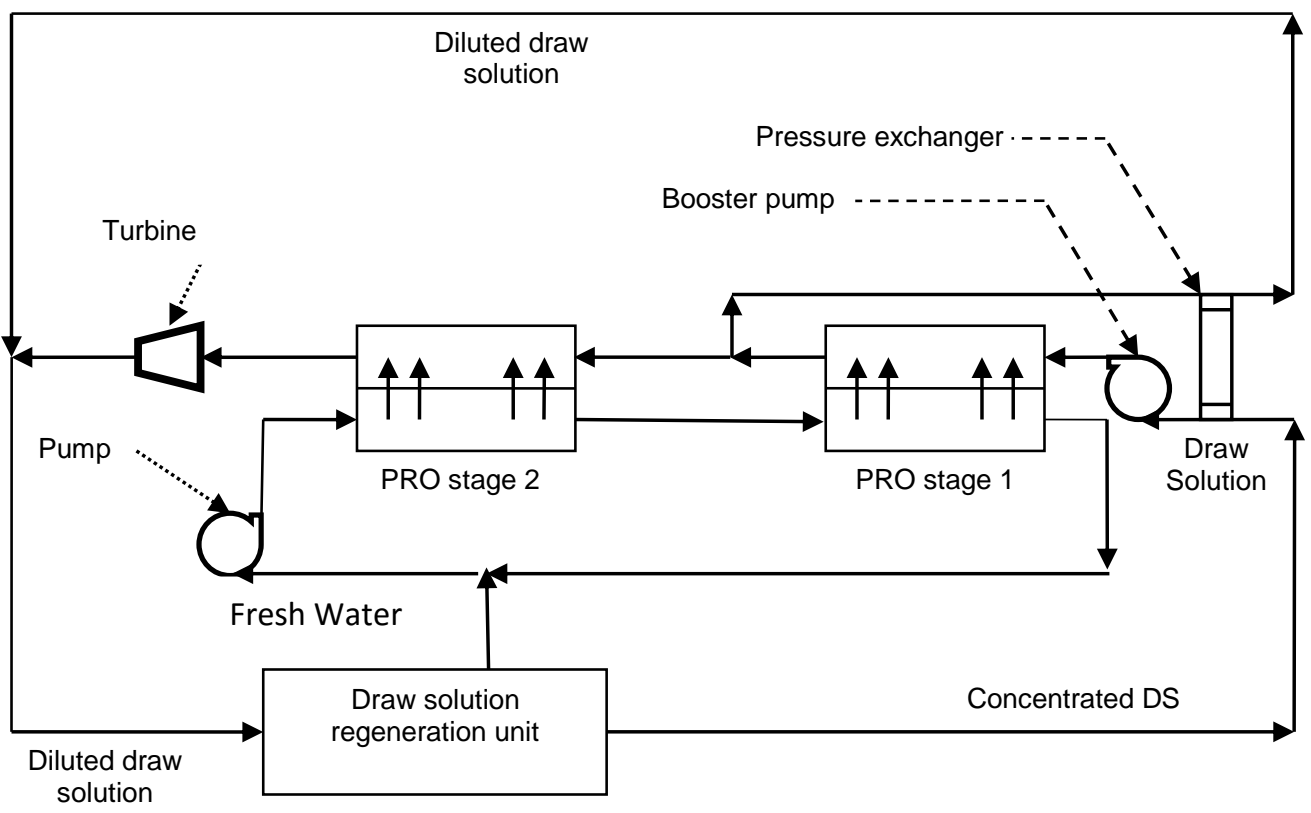




\section{Systems Modeling}

This section describes the models used for the optimization of the PRO system and the methodology used for the process simulation.

\subsection{PRO system}

Single and DSPRO were evaluated for a CLPRO process for power generation. Figures $1 \mathrm{~A}$ and $1 \mathrm{~B}$ show the schematic diagram of a single and dual stage CLPRO, respectively. For a single stage PRO, the membrane flux, DS concentration, recovery rate and power density were optimized taking into account the effect of membrane area, draw solution pressure and DS flow rate on the performance of the PRO process. The following equations were applied for estimating the performance and the power generation of a single stage CLPRO process [23]. Initially, the membrane area and the draw solution pressure were assumed and the PRO permeate flow rate, $Q_{p 1}$, was estimated by the following expression [22]:

$$
Q_{P 1}=A_{m 1} * A_{w}\left(\frac{\pi_{D b 1} * e^{\frac{-\left(Q_{P 1} / A\right)}{k}}-\pi_{F b 1} * e^{\frac{Q_{P 1}}{A} K}}{1+\frac{B}{\frac{Q_{P 1}}{A}}\left(e^{\frac{Q_{P 1}}{A} K}-e^{\frac{-\left(Q_{P 1} / A\right)}{k}}\right)}-\Delta P\right)
$$

where, $Q_{P 1}$ is the permeate flow rate (in $\mathrm{m}^{3} / \mathrm{h}$ ), $\pi_{D b 1}$ and $\pi_{F b 1}$ are the osmotic pressures, respectively, of the bulk draw and bulk feed solution (in bar), $k$ is the mass transfer coefficient (in $\mathrm{m} / \mathrm{s}$ ), $A_{m 1}$ is the PRO membrane area $\left(\mathrm{m}^{2}\right), A_{w}$ is water permeability coefficient (in $\mathrm{L} / \mathrm{m}^{2} \mathrm{~h}$ bar), $\Delta P$ is the hydraulic pressure across the PRO membrane (in bar), $K$ is the solute resistivity for diffusion within the porous support layer (in $\mathrm{s} / \mathrm{m}$ ), and $B$ is the solute permeability coefficient (in $\mathrm{m} / \mathrm{h}$ ). Equation 1 estimates water flux when the draw solution is facing the membrane active layer (DS-AL) to reduce the effect of internal concentration polarization and salt accumulation in the membrane porous layer. However, it does not include the effect of external concentration polarization at the surface of porous layer at the feed side of the PRO membrane. A recent study by Nagy [28] demonstrated the impact of external mass transfer resistance on the performance of PRO process. Interestingly, internal concentration polarization becomes less severe at high cross flow velocities hence the simulations in the present work were performed at high cross flow velocities. It should be mentioned that Equation 1 was developed to predict the performance of flat sheet PRO membrane and there is not experimental formula to calculate the membrane flux in a full scale PRO module yet. Furthermore, $\pi_{F b 1}$ was assumed zero because the feed solution in the CLPRO process is a distilled water; i.e. $\pi_{F b 1}$ $<<\pi_{D b 1}$. It was also assumed that the operating hydraulic pressure was the 
170 average osmotic pressure between $\pi_{F b 1}$ and $\pi_{D b 1}$, hence $\pi_{D b 1}$ was calculated from

171 the following equation [21]:

Water flux, $J_{w 1}$ (in $\mathrm{L} / \mathrm{m}^{2} \mathrm{~h}$ ), is a function of the permeate flow and the membrane area; i.e. $J_{w 1}=Q_{p 1 /} A_{m}$. Van't Hoff equation was used for estimating the osmotic pressure of the bulk draw solution [29]:

$$
\pi_{D b 1}=1.12(273+T) \sum m_{n}
$$

where, $T$ is feed temperature (in Kelvin), $m_{n}$ is the molar concentration of $n^{\text {th }}$ ion species. It should be mentioned that $\mathrm{NaCl}$ was proposed as the DS of CLPRO process in this study. Equation 3 can be re-arranged to estimate $\pi_{D b 1}$ in $\mathrm{mg} / \mathrm{L}$ as the following equation:

$$
\pi_{D b 1}=\frac{C_{N a b} * 1.12 * T}{M w_{N a} * 14.5}+\frac{C_{C l b} * 1.12 * T}{M w_{C l} * 14.5}
$$

$$
C_{C l b}=\frac{M w_{C l}}{M w_{N a}} C_{N a b}=1.54 C_{N a b}
$$

$$
C_{N a b}=\frac{\pi_{D b 1}}{\left(\frac{1.12 T}{M w_{N a} * 14.5}\right)+\left(\frac{1.12 * 1.54 * T}{M w_{C l} * 14.5}\right)}
$$

where, $C_{\mathrm{Nab}}$ is the bulk concentration of $\mathrm{Na}$ ions (in $\mathrm{mg} / \mathrm{L}$ ), $M w_{\mathrm{Na}}$ and $M w_{\mathrm{Cl}}$ are the molecular weight of $\mathrm{Na}$ and $\mathrm{Cl}$ ions (in $\mathrm{mg} / \mathrm{M}$ ), respectively, and $\mathrm{C}_{\mathrm{Clb}}$ is the bulk concentration of $\mathrm{Cl}$ ions (in $\mathrm{mg} / \mathrm{L}$ ).

On the other hand, the inlet concentration of the draw solution, $C_{D i 1}$, was estimated from the mass and flow balance equation in the draw solution side of the membrane:

$$
C_{D i 1} * Q_{D i 1}+C_{P 1} * Q_{P 1}=C_{D o 1} * Q_{D o 1}
$$

$$
C_{D o 1}=2 * C_{D b 1}-C_{D i 1}
$$

$$
C_{D b 1}=\frac{C_{D i 1}+C_{D o 1}}{2}
$$


where $C_{P 1}$ is the permeate concentration (in $\mathrm{mg} / \mathrm{L}$ ). Assuming that $C_{P 1}$ is negligible, $C_{P 1}<<C_{D 01}$ and $C_{D i 1}$, and replacing equation 8 in equation 7 :

$$
C_{D i 1} * Q_{D i 1}=\left(2 * C_{D b 1}-C_{D i 1}\right) * Q_{D o 1}
$$

$$
C_{D i 1}=\frac{2 * C_{D b 1} * Q_{D o 1}}{Q_{D i 1}+Q_{D o 1}}
$$

where, $C_{D o 1}$ is the outlet concentration of the DS (in $\mathrm{mg} / \mathrm{L}$ ), $C_{D i 1}$ is the inlet concentration of the DS (in $\mathrm{mg} / \mathrm{L}$ ), $Q_{D 01}$ is the outlet flow rate of the $\mathrm{DS}$ (in L/h), $Q_{D i 1}$ is the inlet flow rate of the DS (in $\mathrm{L} / \mathrm{h}$ ), and $C_{P}$ is the permeate concentration (in $\mathrm{mg} / \mathrm{L}$ ). Eventually, $C_{D o 1}$ was calculated from replacing the value of $C_{D i 1}$ from equation 11 in equation 8 . The power density, $W_{1}$ (in $\mathrm{W} / \mathrm{m}^{2}$ ), was calculated from equation 12 as follows:

$W_{1}=J_{w 1} * \Delta P$

The power generation, $P_{w}$ (in $\mathrm{kW}$ ), by the PRO process was calculated from the following equation:

$P_{w 1}=Q_{P 1} * \Delta P$

Finally, the PRO recovery rate, $R e_{1}$, was calculated from the following equation:

$\operatorname{Re}_{1}=\frac{Q_{P 1}}{Q_{F 1}}$

where, $Q_{F 1}$ is the feed flow rate (in $L / h$ ).

In the case of the dual stage, the diluted DS from the first stage of the DSPRO process is divided into two streams after leaving the membrane [see Figure 1B]. The first stream goes back to a pressure exchanger to pressurize the DS. The second stream, with a volume equals to $Q_{P 1}$, will be the draw solution of the second stage of the DSPRO process [Figure 2B]. This means that the flow rate of the DS in the second stage is equal to $Q_{P 1}$. Furthermore, the hydraulic pressure of the first stage is equal to that of the second stage of the DSPRO process, assuming insignificant pressure losses in the first stage. The performance of the second stage of the PRO process was estimated using the following assumptions:

1. Membrane area in the second stage of the DSPRO process is calculated as the ratio of osmotic pressure driving force of the second stage to that of the first stage multiplied by $A_{m 1}$; i.e. $A_{m 2}=A_{m 1}\left(\Delta \pi_{2} / \Delta \pi_{1}\right)$. 
$J_{w 2}=A_{w}(\Delta \pi-\Delta P)$

where, $A_{w}$ is the water permeability coefficient (in L/m² $\mathrm{h}$.bar), $\Delta \pi$ is the osmotic pressure gradient (in bar), and $\Delta P$ is the hydraulic pressure difference (in bar). Likewise, the permeate flow rate in the second stage of the PRO process, QP2, was calculated as:

$Q_{P 2}=J_{w 2} * A_{m 2}$

where $A_{m 2}$ is the membrane area in the second stage of the DSPRO process (in $\left.\mathrm{m}^{2}\right)$. Noting that, $Q_{D 02}$ is the sum of $Q_{D i 2}$ and $Q_{P 2}$. Assuming $C_{P 2}<C_{D i 2}$, the outlet concentration of the draw solution, $C_{D 02}$, was calculated from the concentration and mass balance on the DS side of the second stage of the DSPRO membrane:

$$
C_{D o 2}=\frac{Q_{D i 2} * C_{D i 2}}{Q_{D o 2}}
$$

where, $C_{D i 2}$ is the concentration of the DS in second stage (in $\mathrm{mg} / \mathrm{L}$ ). The outlet osmotic pressure of the DS, $\pi_{D o 2}$ (in bar), was calculated from the following equation:

$278 \quad \pi_{D o 2}=\frac{C_{D o 2} * \frac{M w_{N a}}{M w_{N a C l}} * 1.12 * T}{M w_{N a} * 14.5}+\frac{C_{D o 2} * \frac{M w_{C l}}{M w_{N a C l}} * 1.12 * T}{M w_{C l} * 14.5}$

279

$283 \quad \pi_{D b 2}=\frac{\pi_{D i 2}+\pi_{D o 2}}{2}$

where, $M w_{\mathrm{NaCl}}$ is the molecular weight of $\mathrm{NaCl}$ (in $\mathrm{mg} / \mathrm{mol}$ ). The bulk concentration of the DS, $\pi_{D b 2}$, was estimated from the following equation:

where $\pi_{D i 2}$ is the inlet osmotic pressure of the DS in the second stage (in bar). Then, the membrane flux of the second stage of the DSPRO, Jw2, was estimated from equation 20: 
$289 J_{w 2}=A_{w}\left(\frac{\pi_{D b 2} * e^{\frac{-J_{W 2}}{k}}-\pi_{F b 2} * e^{J_{W 2} K}}{1+\frac{B}{J_{w 2}}\left(e^{J_{W 2} K}-e^{\frac{-J_{W 2}}{k}}\right)}-\Delta P\right)$

290

291 In this case, the power density, $W_{2}$ (in $\mathrm{W} / \mathrm{m}^{2}$ ), was estimated from equation 21 :

292

293

$W_{2}=J_{w 2} * \Delta P$

294

295 The power generation of the second stage of the DSPRO, $P_{w 2}$ (in $\mathrm{kWh}$ ), and the

296 recovery rate, $\operatorname{Re}_{2}(\%)$, were estimated from equations 22 and 23 , respectively:

297

298

$P_{w 2}=Q_{P 2} * \Delta P$

299

$300 \quad \operatorname{Re}_{2}=\frac{Q_{P 2}}{Q_{F 2}}$

301

302

303

where, $Q_{F 2}$ is the feed flow rate of the second stage of the DSPRO process $(\mathrm{L} / \mathrm{h})$.

304 The performance of the second stage of the PRO process was estimated by 305 applying the iteration method described in [Figure 2]. 


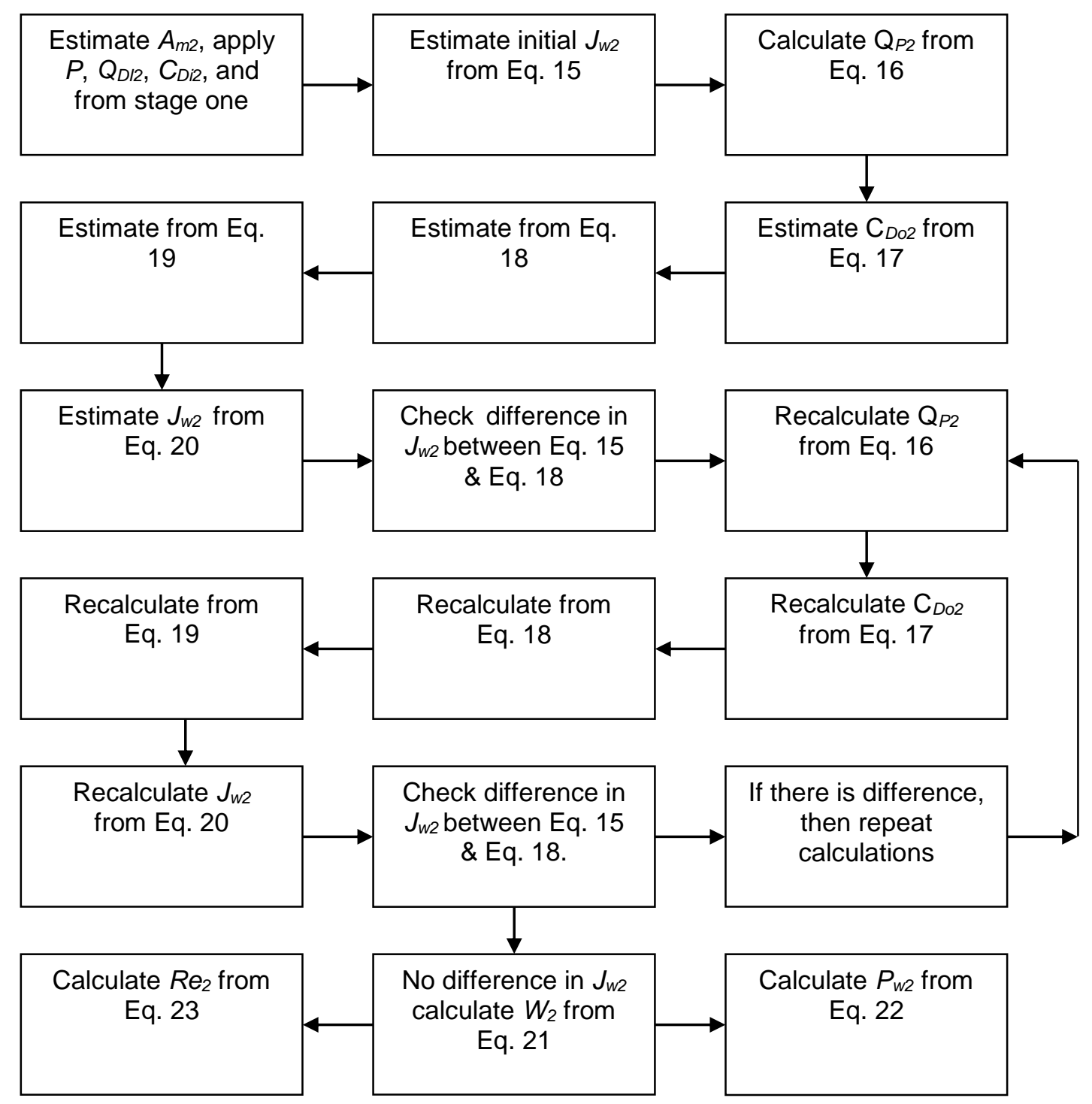

Figure 2: Schematic diagram that illustrates the steps for estimating the performance of the second stage of the PRO process

\subsection{Thermal system}

The main option that has been considered for regeneration of draw solution is Multiple Effect Distillation (MED) which represents the most efficient evaporative technology in the desalination industry [33-34]. The potential for improving its energy efficiency is large, especially by increasing the operating temperature over $70^{\circ} \mathrm{C}$. Higher operating temperatures will result in the precipitation of sparingly-soluble metal salts in the seawater. We assumed that a source of waste heat is already available for the MED regeneration process. 
The MED process consists in a series of under vacuum evaporators (also called effects) at decreasing pressure and temperatures, in which vapour is generated in one effect and condensed in the following one. The thermal energy source that drives the evaporation process in all effects is the vapour generated in the previous effect, except in the first one where an external heat source is required. Distillate is obtained in all evaporators from the condensation of the vapour and then it is directed to flash boxes in order to exploit its heat content. The remaining feed water that has not been evaporated passes from one effect to other hence gets more concentrated.

The MED system simulated in this work is forward-feed (see Figure 3 ). In this design, the vapour and feed solution go in the same direction, from the highest temperature effect to the lowest temperature effect. Another characteristic of this design is the preheating of feed solution before the starting point of the process. Shell and tube heat exchangers are used; feed solution circulates inside the tubes and a small part of the vapour generated from the evaporator condenses on the external surface to produce distillate and preheats the feed.

A computer model was developed to calculate the MED performance based on energy and mass balances of the feed streams [35-36]. The model was validated taking into account operating conditions such as Top Brine Temperature (TBT), inlet salinity and recovery ratio [36]. For the current study, model operation conditions were modified hence allowing for higher TBT and recovery ratios than those for seawater desalination, since no fouling is expected in the process of DS regeneration. The computation of model as well as the equations and the considered boundary conditions are explained below.

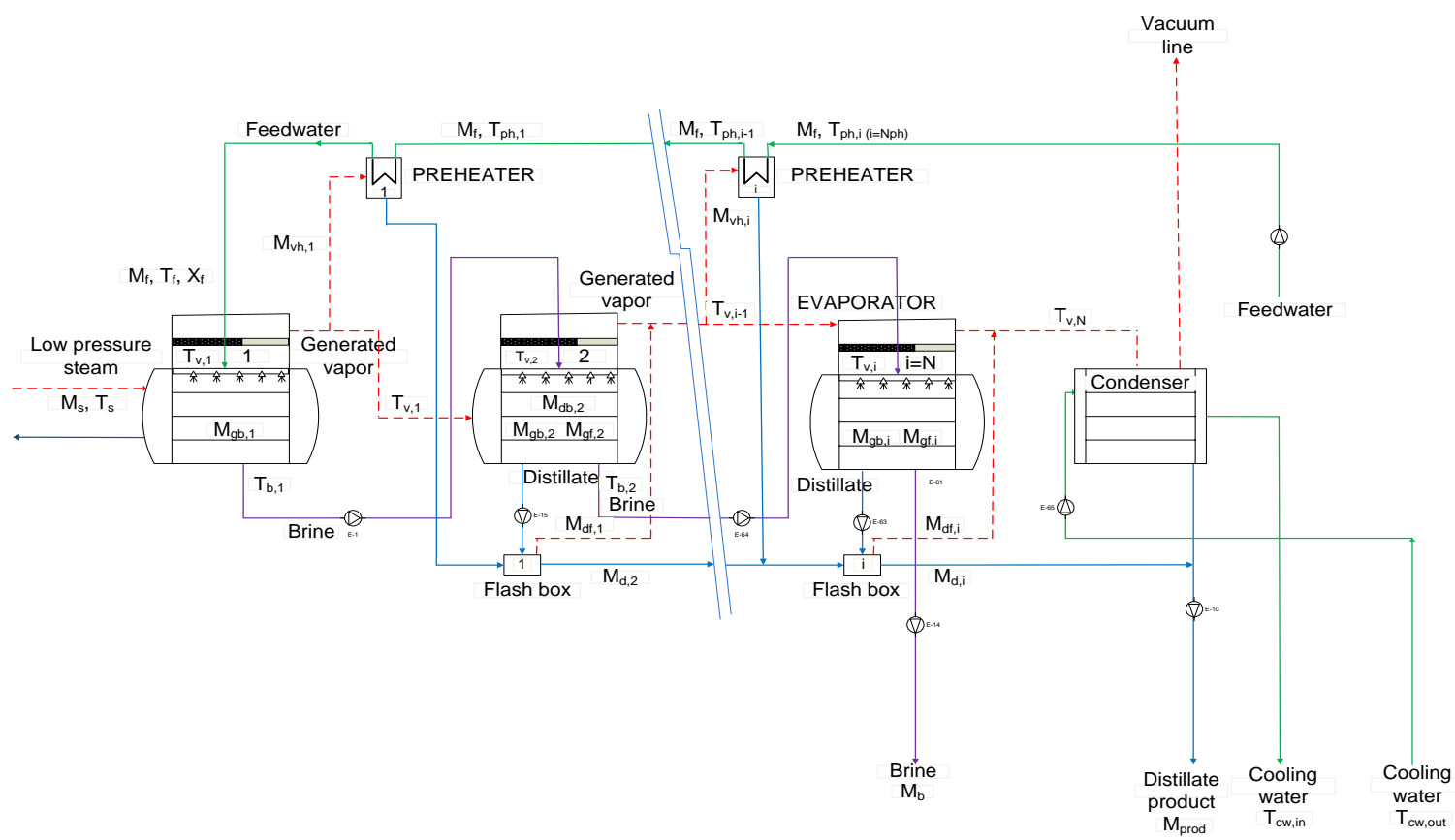

Figure 3: Layout of the forward-feed MED plant considered in this work. 
There are two options for the design models of MED plants: firstly, to establish equal areas in all the effects and secondly, to consider constant temperature difference across the effects. The first option is used for constraining the size of the effects which is desired to decrease the capital cost of the MED. In this model, unlike that described in our previous work [36], equal area in all effects was considered. For the computation of the model, an iteration loop was implemented in the Matlab software that starts with the temperature profile and continues until a convergence criterion is achieved. The convergence criterion of the model should have a maximum difference in effect areas of $1^{\star} 10^{-4}$ in order to achieve a good accuracy.

The temperature profile was initially obtained considering equal temperature difference $\left(\Delta T_{e f f_{i}, i}\right)$ in all the effects, which was determined as the following:

$$
\Delta T_{e f f, i}=\frac{T_{v, 1}-T_{v, N}}{N-1}
$$

where $N$ is the number of effects, $T_{v, 1}$ is the vapor temperature generated in the $1^{\text {st }}$ effect and $T_{v, N}$ is the vapor temperature generated in the last effect. The Top Brine Temperature (TBT) is the maximum temperature reached in the first evaporator, which corresponds to the maximum temperature of the unevaporated brine solution through the MED $\left(T_{b, 1}\right)$. This temperature is higher than that of the vapour generated in the evaporator $\left(T_{v, 1}\right)$ due to the boiling point elevation $(B P E)$. This parameter increases with the increase in the content of salts in the treated solution. For the rest of evaporators, the brine temperature was also determined by the temperature of vapour produced inside the evaporator and the corresponding BPE.

The performance of the MED plant is evaluated by the Recovery Ratio $(R R)$ and the specific thermal consumption, $S_{T C}$. On one hand, the recovery ratio is the ratio of the distillate product to the feed flow rate supplied:

$R R=\frac{M_{\text {prod }}}{M_{f}}$

where $M_{\text {prod }}$ is the total distillate flow rate obtained from the MED plant.

On the other hand, the specific thermal consumption is defined as the thermal energy supplied to the distillation unit for every $\mathrm{m}^{3}$ of distillate produced:

$$
S_{T C}=\frac{Q_{\text {eff }, 1}}{M_{\text {prod }}}
$$

The total distillate flow rate was determined as the sum of the flows leaving the flash boxes (see Appendix 1): 


$$
M_{\text {prod }}=\sum_{i=2}^{N} M_{d, i}
$$

The heat transfer provided to the first effect $\left(Q_{\text {eff }, 1}\right)$ was calculated by the energy balance equation as in the following equation:

$$
Q_{e f f, 1}=M_{g b, 1} \lambda_{g b, 1}+M_{f} C_{p}\left(T_{b, 1}-T_{f}\right)=M_{s} \lambda_{s}
$$

where $T_{f}$ is the temperature of feed water sprayed in the first effect of MED, $M_{s}$ is the mass flow rate of low pressure steam and $\lambda_{s}$ is the change in enthalpy related to the vapour condensation.

The model was run considering the salinity and feed solution flow rate to the MED plant and the recovery ratio as inputs. The first two are given by the characteristics of the DS as it exits the PRO, and the third is the required concentration for the regeneration. The model results give first the number of effects $(N)$ and the TBT that keep the temperature difference between the MED effects $\left(\Delta T_{\text {eff }, i}\right)$ in the range of $2-3^{\circ} \mathrm{C}$, which is the usual driving force used in MED plants to achieve good thermal efficiencies. Then, it gives the specific thermal energy consumption, the area of the evaporators and the temperature profile through the evaporators.

The following assumptions were considered in the model:

- Temperature difference of cooling water between the inlet $\left(T_{\text {cwin }}\right)$ and the outlet $\left(T_{\text {cw,out }}\right)$ through the end condenser was $7.3^{\circ} \mathrm{C}$

- Cooling water inlet temperature $\left(T_{\text {cwin }}\right)$ was $25^{\circ} \mathrm{C}$

- The temperature difference between the feed solution $\left(T_{f}\right)$ and the vapour generated inside $1^{\text {st }}$ effect $\left(T_{v, 1}\right)$ was $3^{\circ} \mathrm{C}$.

- The initial (before the iteration loop) temperature difference between the low pressure steam $\left(T_{s}\right)$ and the vapour in the $1^{\text {st }}$ effect $\left(T_{v, 1}\right)$ was established as $4^{\circ} \mathrm{C}$. Then, it changed once and the new temperature profile was generated by the equal effect areas iteration loop.

\section{Results and discussion}

\subsection{Model Calibration}

The PRO model was calibrated using experimental data [12]. The membrane flux, $J_{w}$, and the power density, $W$, were calculated and compared with the experimental results [22], using draw solution pressures close to the optimum value of $\Delta P=\Delta \pi / 2$. In order to evaluate the impact of the draw solution pressure on the accuracy of the PRO model, a wide range of hydraulic pressures was 
used for the calibration of the PRO model in the current study. Table 1 shows the testing parameters for calibrating the PRO model using a cellulose triacetate FO membrane manufactured by Hydration Technology Innovations, USA [22]. It was assumed that the same type of PRO membrane was used in the first and the second stage of the DSPRO process.

Table 1: PRO model testing parameters

\begin{tabular}{|c|c|c|c|c|}
\hline Parameter & $\mathbf{k}(\mathbf{m} / \mathbf{h})$ & $\mathbf{K}(\mathbf{h} / \mathbf{m})$ & $\mathbf{A}_{\mathbf{w}}(\mathbf{m} / \mathbf{h}$. bar $)$ & $\mathbf{B}(\mathbf{m} / \mathbf{h})$ \\
\hline Value & 0.306 & $115-125$ & $6.7^{*} 10^{-4}$ & $4^{*} 10^{-4}$ \\
\hline
\end{tabular}

$439 J_{w}$ and $W$ are the key performance parameters of the PRO process; these parameters were calculated and compared with the experimental results [22]. The results showed that the experimental and model membrane fluxes, Jw-exp, and $\mathrm{J}_{\mathrm{w} \text {-mod }}$ respectively, were in a good agreement with each other [Table 2]. The percentage difference between $J_{w-e x p}$, and $J_{w-m o d} \%$ Diff $J_{w}$, was between $2.5 \%$ and $9.8 \%$. Apparently, using feed pressures less than $\Delta \pi / 2$ did not affect the 445 model accuracy. Table 2 also shows that the difference between experimental 446 and model power density, $W_{\exp }$ and $W_{\text {mod }}$ respectively, were between $3.5 \%$ and $447 \quad 9.7 \%$. Generally, the difference between model and experimental power densities 448 was less than $10 \%$. It should be noted that the difference between the model and 449 experimental could be due to the fact that the osmotic pressures of the feed 450 solutions in the experimental work were calculated by OLI Systems Inc. (Morris 451 Plains, $\mathrm{NJ}$ ) while the osmotic pressures of the feed solutions in the model were 452 determined by Van't Hoff equation.

453

454

455 Table 2: Model and experimental data of membrane flux and power density 456 * draw solution pressure $\Delta \pi / 2$

\begin{tabular}{|c|c|c|c|c|c|c|c|c|}
\hline $\begin{array}{c}\text { Draw TDS } \\
(g / L)\end{array}$ & $\begin{array}{l}\text { Feed TDS } \\
(\mathrm{g} / \mathrm{L})\end{array}$ & $\begin{array}{c}\text { Pressure } \\
\text { (bar) }\end{array}$ & $\begin{array}{c}J_{w-\exp } \\
\left(L / m^{2} h\right)\end{array}$ & $\begin{array}{l}J_{\mathrm{w}-\mathrm{mod}} \\
\left(\mathrm{L} / \mathrm{m}^{2} \mathrm{~h}\right)\end{array}$ & $\begin{array}{c}\text { \% Diff. } \\
\mathbf{J}_{w}\end{array}$ & $\begin{array}{c}W_{\text {exp }} \\
\left(W / m^{2}\right)\end{array}$ & $\begin{array}{c}W_{\text {mod }} \\
\left(W / m^{2}\right)\end{array}$ & $\begin{array}{c}\text { \% Diff } \\
\text { W }\end{array}$ \\
\hline \multirow[t]{3}{*}{$35^{\star}$} & 0 & 13 & 7.9 & 7.7 & $2.5 \%$ & 2.9 & 2.8 & $3.5 \%$ \\
\hline & 2.5 & 12 & 6.8 & 6.2 & $8.8 \%$ & 2.3 & 2.1 & $8.7 \%$ \\
\hline & 5 & 11 & 5.6 & 5.1 & $8.9 \%$ & 1.7 & 1.55 & $8.8 \%$ \\
\hline \multirow[t]{3}{*}{$60^{*}$} & 0 & 24 & 12.4 & 12 & $3.5 \%$ & 8.3 & 8.0 & $3.6 \%$ \\
\hline & 2.5 & 23 & 10.1 & 9.5 & $5.9 \%$ & 6.5 & 6.1 & $6.1 \%$ \\
\hline & 5 & 22.5 & 8.5 & 7.8 & $8.2 \%$ & 5.3 & 4.9 & $7.5 \%$ \\
\hline \multirow[t]{3}{*}{35} & 0 & 10 & 10.1 & 9.4 & $6.9 \%$ & 2.8 & 2.6 & $7.1 \%$ \\
\hline & 2.5 & 10 & 7.2 & 6.7 & $7.0 \%$ & 2.0 & 1.85 & $7.5 \%$ \\
\hline & 5 & 10 & 5.5 & 5.1 & $7.2 \%$ & 1.6 & 1.4 & $6.7 \%$ \\
\hline
\end{tabular}




\begin{tabular}{|c|c|c|c|c|c|c|c|c|}
\hline 60 & 0 & 15 & 15.8 & 15 & $5.0 \%$ & 6.8 & 6.3 & $7.3 \%$ \\
\cline { 2 - 9 } & 2.5 & 15 & 12.2 & 11 & $9.8 \%$ & 5.0 & 4.6 & $8.8 \%$ \\
\cline { 2 - 9 } & 5 & 15 & 9.6 & 8.9 & $7.2 \%$ & 4.1 & 3.7 & $9.7 \%$ \\
\hline
\end{tabular}

457

458

459

460

461

462

463

464

465

466

467

468

469

470

471

472

473

474

475

476

477

478

479

480

481

482

483

484

485

486

487

488

489

490

491

492

493

494

495

496

\subsection{Single and dual PRO system}

The PRO process optimization was performed taking into account the impact of the membrane area, draw solution pressure, and DS flow rate. The performance of single and dual stage CLPRO was evaluated for comparison purposes. The effect of changing the membrane area on the performance of a single and dual stage CLPRO process is illustrated in [Figure 4]. The applied draw solution pressure was 16 bar and the draw and feed solutions flow rates in the first stage of the PRO process were $5000 \mathrm{~L} / \mathrm{h}$. PRO mode membrane orientation was selected because of the higher PRO performance [21, 27]. For the single stage CLPRO, the increase of the membrane area resulted in a minor increase in the water flux of the first stage, $J_{w 1}$. This was accomplished by increasing the inlet concentration of DS, $C_{D i 1}$, and the osmotic pressure, $\pi_{D i 1}$ of the first stage [Figure $4 a$ and $4 b]$. $J_{w 1}$ increased from $11.2 \mathrm{~L} / \mathrm{m}^{2} \mathrm{~h}$ to $11.6 \mathrm{~L} / \mathrm{m}^{2} \mathrm{~h}$ as membrane area increased from $200 \mathrm{~m}^{2}$ to $300 \mathrm{~m}^{2}$, respectively, because of the larger permeate flow. The corresponding inlet DS concentrations, $C_{D i 1}$, were $0.86 \mathrm{~mol} / \mathrm{L}$ and 0.92 $\mathrm{mol} / \mathrm{L}$, respectively. Practically, the modulus of external CP (ECP), $e^{\frac{-J_{w}}{k}}$, on the DS side of the membrane approaches a unity at negligible ECP. The results show [Figure 4c] that $e^{\frac{-J w}{k}}$ decreased slightly below a unity with the increase in the membrane area indicating a higher ECP effect. Therefore, $C_{D i 1}$ was slightly increased with the increase of membrane area in order to maintain $J_{w 1}$ [Figure $4 a$ and $4 \mathrm{~b}]$.

For a DSPRO process, the high membrane flux in the first stage increased the dilution of DS which in turn affected the water flux in the second stage of the DSPRO, $J_{w 2}$ [Figure 4a]. Simulation results show that $J_{w 2}$ decreased from 5.0 $\mathrm{L} / \mathrm{m}^{2} \mathrm{~h}$ to $4.0 \mathrm{~L} / \mathrm{m}^{2} \mathrm{~h}$ due to the increase of first stage membrane area, $A_{m 1}$, from $200 \mathrm{~m}^{2}$ to $300 \mathrm{~m}^{2}$. This was attributed to the lower osmotic pressure across the PRO membrane. The osmotic pressure of the DS in the second stage, $\pi_{D i 2}$, decreased from 26 bar to 23.7 bar whereas $C_{D i 2}$ decreased from $0.58 \mathrm{~mol} / \mathrm{L}$ to $0.52 \mathrm{~mol} / \mathrm{L}$ as $A_{m 1}$ increased from $200 \mathrm{~m}^{2}$ to $300 \mathrm{~m}^{2}$, respectively [Figure $4 \mathrm{a}$ and 4b]. Furthermore, simulation results revealed that $e^{\frac{-J_{w}}{k}}$ of the second stage of the DSPRO process increased from 0.98 to 0.99 with the increase in the membrane area, which was an indicative to the lower CP effect. In effect, the decrease of $J_{w 2}$ resulted in a lower dilutive ECP at the DS side of the second stage of the CLPRO process. 
Recovery rates of the first and second stage of the CLPRO process are illustrated in [Figure 4d]. Results reveal that the recovery rates of the first and the second stage of the DSPRO, $\mathrm{Re}_{1}$ and $\mathrm{Re}_{2}$, increased with the increase in the

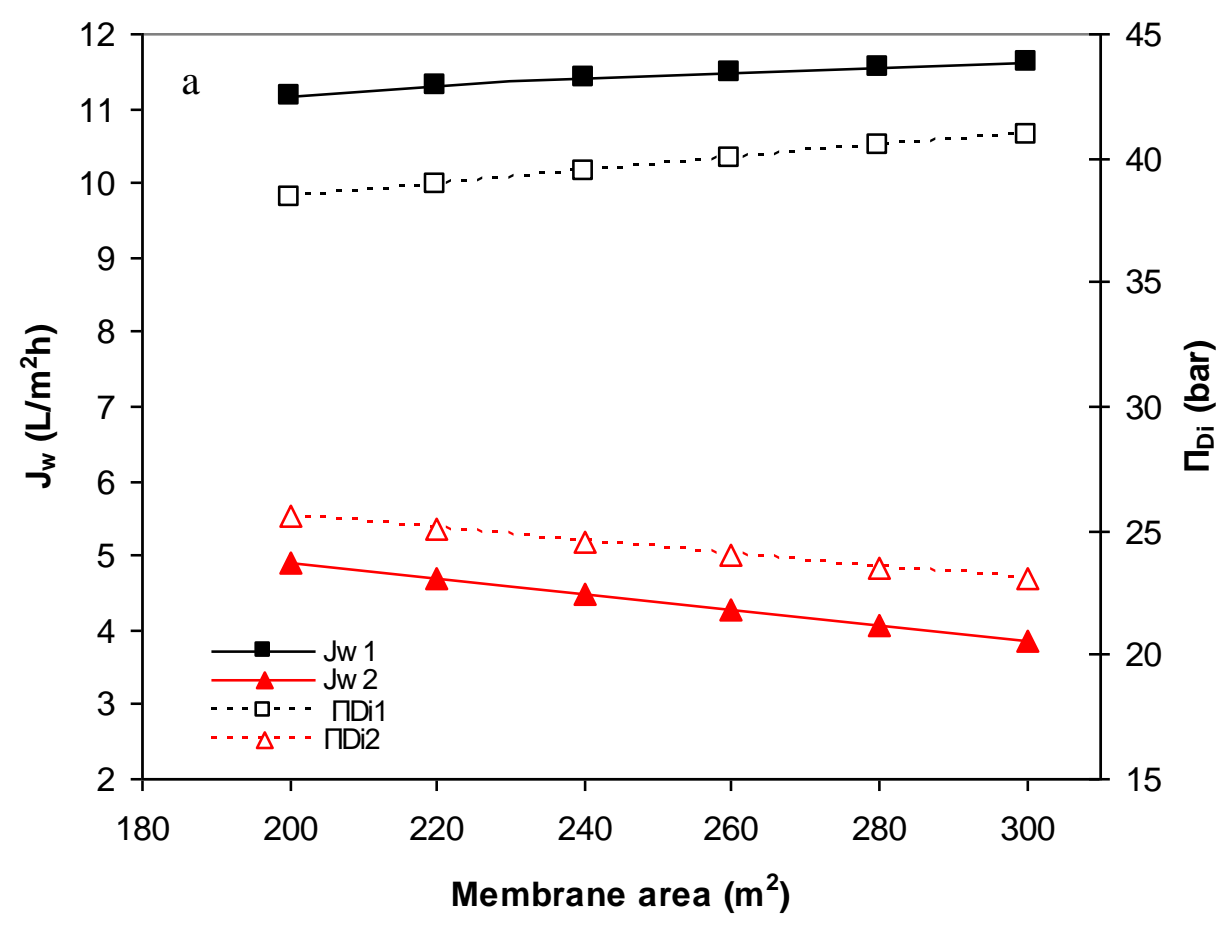
$A_{m 1}$. In this way, $\operatorname{Re}_{1}$ was $45 \%$ at $200 \mathrm{~m}^{2}$ membrane area and increased to $70 \%$ at $300 \mathrm{~m}^{2}$, whereas $\mathrm{Re}_{2}$ increased from $27 \%$ to $51 \%$ as $A_{m 1}$ increased from 200 $\mathrm{m}^{2}$ to $300 \mathrm{~m}^{2}$. The total recovery rate of the DSPRO, Re-tot, was $60 \%$ at $200 \mathrm{~m}^{2}$ and increased to $85 \%$ at $300 \mathrm{~m}^{2}$. Furthermore, the power density of the first and second stage, $W_{1}$ and $W_{2}$ respectively, were estimated and illustrated in [Figure 4e]. Simulation results revealed that $W_{1}$ increased from $6 \mathrm{~W} / \mathrm{m}^{2}$ to $6.5 \mathrm{~W} / \mathrm{m}^{2}$ as $A_{m 1}$ increased from $200 \mathrm{~m}^{2}$ to $300 \mathrm{~m}^{2}$, whereas $W_{2}$ decreased from $2.8 \mathrm{~W} / \mathrm{m}^{2}$ to $2.3 \mathrm{~W} / \mathrm{m}^{2}$ as $A_{m 1}$ increased from $200 \mathrm{~m}^{2}$ to $300 \mathrm{~m}^{2}$ [Figure 4e]. The increase and decrease, respectively, of $W_{1}$ and $W_{2}$, reflected the increase and decrease of $J_{w 1}$ and $J_{w 2}$, respectively. The higher the water flux the higher the power density produced by the PRO membrane. Finally, results show that $W_{2}$ was $45 \%$ of $W_{1}$ at $200 \mathrm{~m}^{2}$ and decreased to $35 \%$ of $W_{1}$ at $300 \mathrm{~m}^{2}$. For the rest of this study, $A_{m 1}$ was assumed $300 \mathrm{~m}^{2}$ because of the high PRO performance and power density, especially in the first stage; i.e. $\left(W_{1} \sim 3 W_{2}\right)$. 


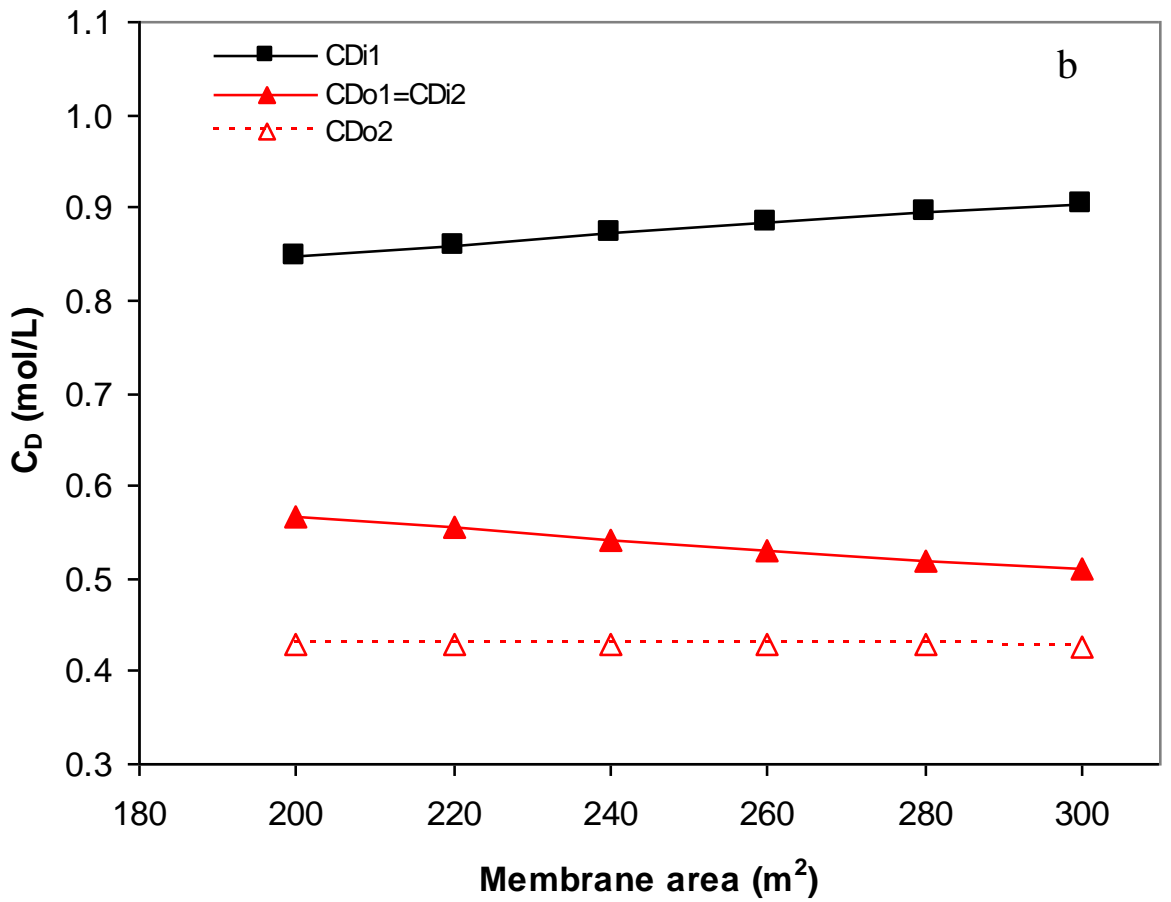

520

521

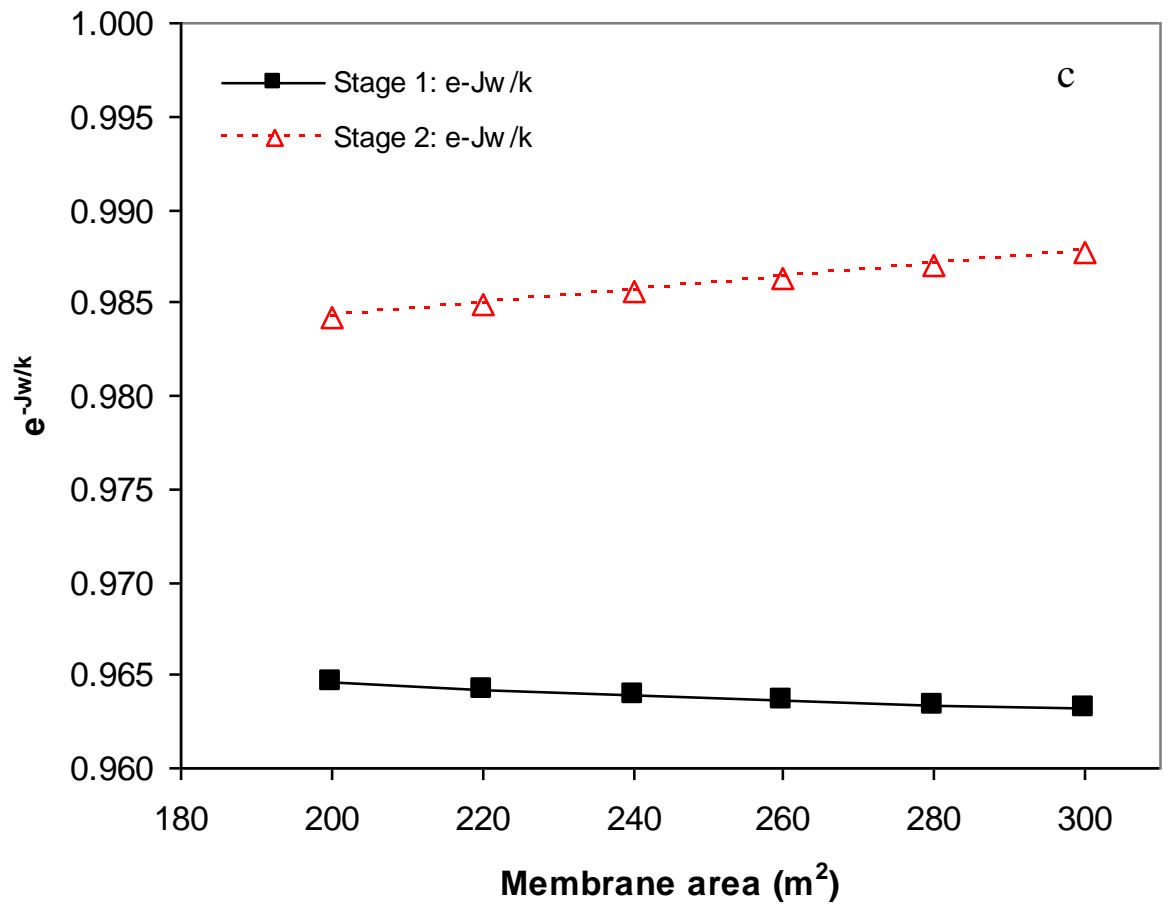




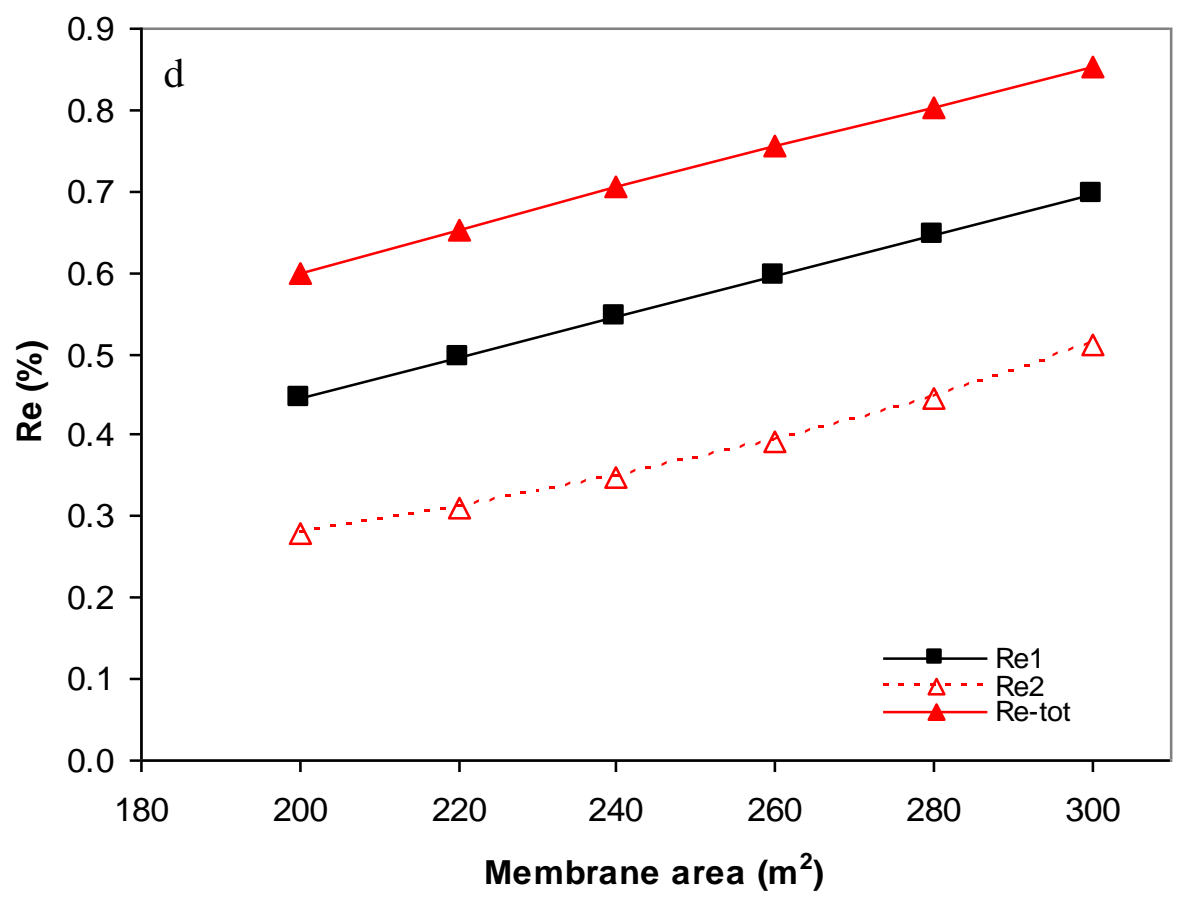

528

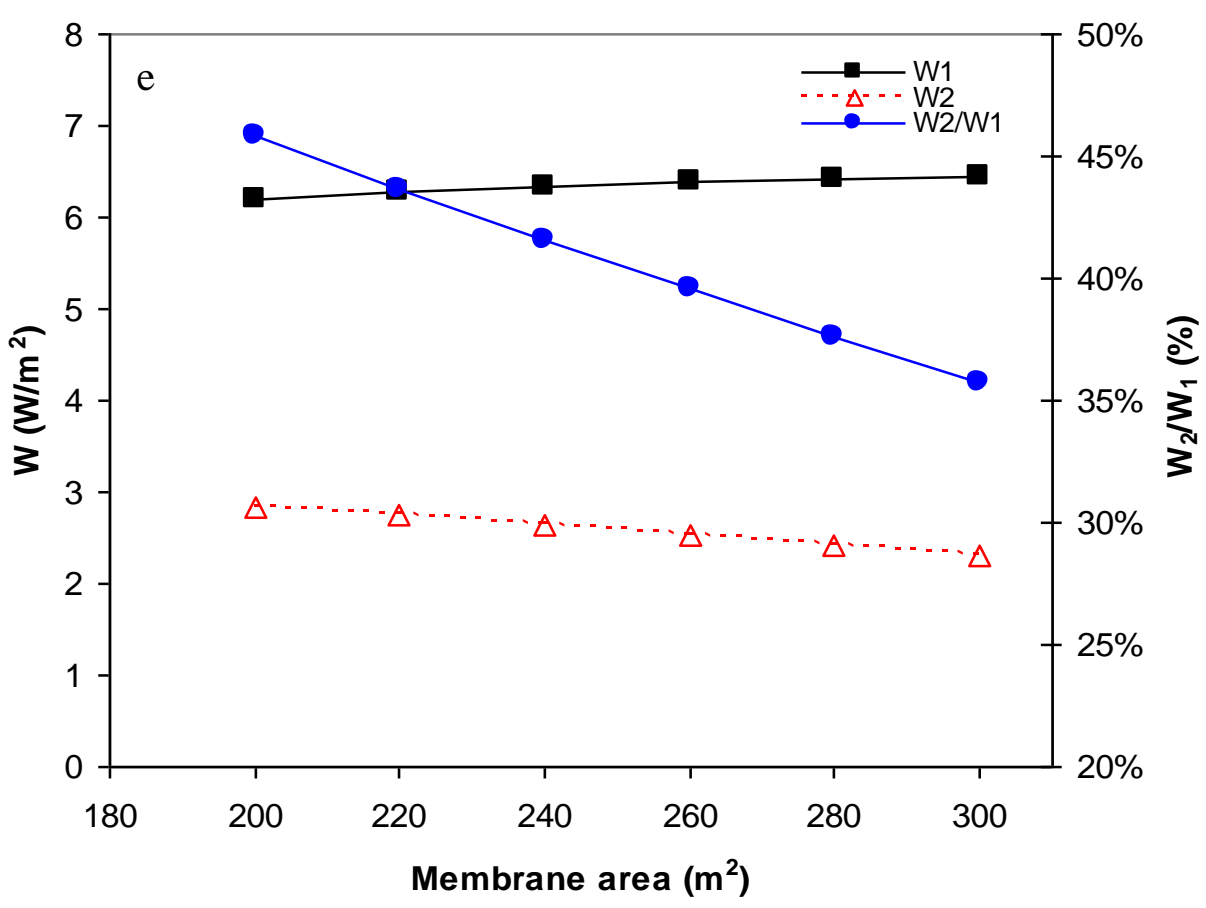

530 Figure 4: Impact of membrane area on single and dual stage PRO process a) impact on the water flux and DS concentration b) effect of inlet and outlet concentration polarization d) effect on recovery rate of single and dual stage CLPRO e) effect on power density 
536 The effect of hydraulic pressure, $P$, on the performance of the first and second 537 stages of the DSPRO process is illustrated in [Figure 5]. The performance of the CLPRO process was modelled for a membrane area of $300 \mathrm{~m}^{2}$ and $5000 \mathrm{~L} / \mathrm{h}$ for $Q_{D i 1}$ and $Q_{F i 1}$. Water flux of the first stage of the DSPRO process, $J_{w 1}$, increased from $7.2 \mathrm{~L} / \mathrm{m}^{2} \mathrm{~h}$ to $11.6 \mathrm{~L} / \mathrm{m}^{2} \mathrm{~h}$ as draw solution pressure increased from 10 bar to 16 bar, respectively [Figure 5a]. This was due to the increase of the inlet concentration of DS, $C_{D i 1}$, and the osmotic pressure, $\pi_{D i 1}$, of the first stage of the DSPRO process. For example, $C_{D i 1}$ increased from $0.5 \mathrm{~mol} / \mathrm{L}$ to $0.9 \mathrm{~mol} / \mathrm{L}$ as the draw solution pressure increased from 10 bar to 16 bar; the corresponding $\pi_{D i 1}$ was 24 bar and 40 bar, respectively [Figure 5b]. For a PRO process operating at maximum power density, the draw solution pressure increased with the increase in the osmotic pressure of the salinity gradient resource. In effect, the increase of $C_{D i 1}$ was essential to provide a sufficient driving force for the increase of $J_{w 1}$. Furthermore, the effect of the draw solution pressure on the ECP of the first stage was illustrated in [Figure 5c]. $e^{\frac{-J_{w}}{k}}$ function deviated away from a unity with the increase in the draw solution pressure, which indicated a high ECP effect.

For the second stage of the DSPRO process, increasing the draw solution pressure from 10 bar to 16 bar resulted in a slight increase of $J_{w 2}$ from $3.2 \mathrm{~L} / \mathrm{m}^{2} \mathrm{~h}$ to $4.1 \mathrm{~L} / \mathrm{m}^{2} \mathrm{~h}$. This was attributed to the increase of $C_{D i 2}$ and $\pi_{D i 2}$, which resulted in a higher $J_{w 2}$ [Figures $5 a$ and $\left.5 b\right]$. Furthermore, $e^{\frac{-J_{w}}{k}}$ was decreased slightly below a unity as an indicative of the higher ECP effect on the DS side, which was caused by the high $J_{w 2}$ [Figure $5 c$ ]. The results also show that the recovery rate of first and second stage, $\mathrm{Re}_{1}$ and $\mathrm{Re}_{2}$ respectively, increased with the increase of the draw solution pressure from 10 bar to 16 bar. The total recovery rate of the DSPRO, i.e. the sum of $\mathrm{Re}_{1}$ and $\mathrm{Re}_{2}$, increased from $58 \%$ to $85 \%$ due to the increase of draw solution pressure from 10 bar to 16 bar. Regarding PRO power density, the results are shown in [Figure 5e]. $W_{1}$ increased about 2.5 times, from $2.5 \mathrm{~W} / \mathrm{m}^{2}$ to $6.46 \mathrm{~W} / \mathrm{m}^{2}$, due to the draw solution pressure increase from 10 bar to 16 bar whereas $W_{2}$ was doubled, from $1.1 \mathrm{~W} / \mathrm{m}^{2}$ to $2.3 \mathrm{~W} / \mathrm{m}^{2}$, due to the increase of draw solution pressure from 10 bar to 16 bar. In general, $W_{2}$ was about $45 \%$ and $35 \%$ of $W_{1}$ at draw solution pressures 10 bar and 16 bar, respectively. The results show that the performance of the DSPRO process was higher at a draw solution pressure of 16 bar and a $A_{m 1}$ of $300 \mathrm{~m}^{2}$. 


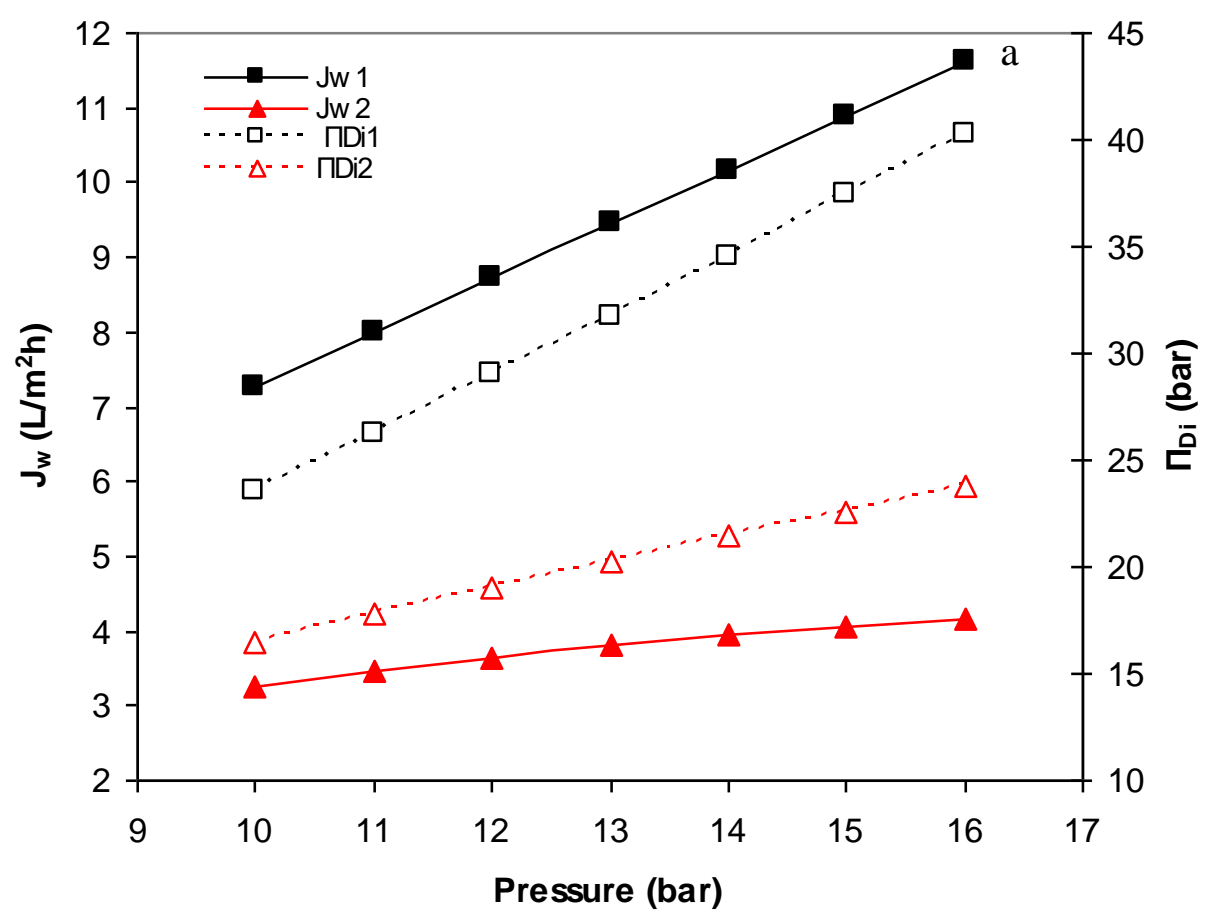

573

574

575

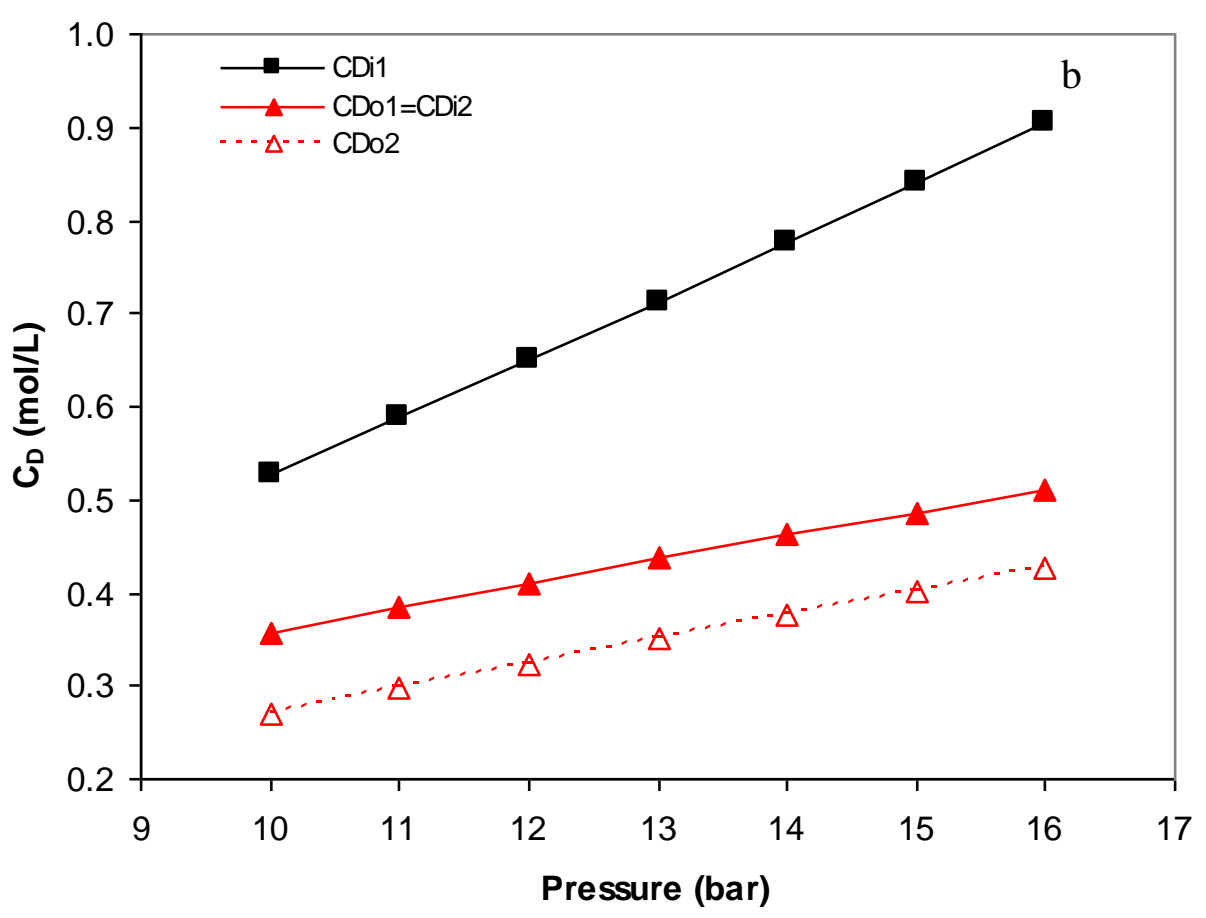

576

577

578

579 

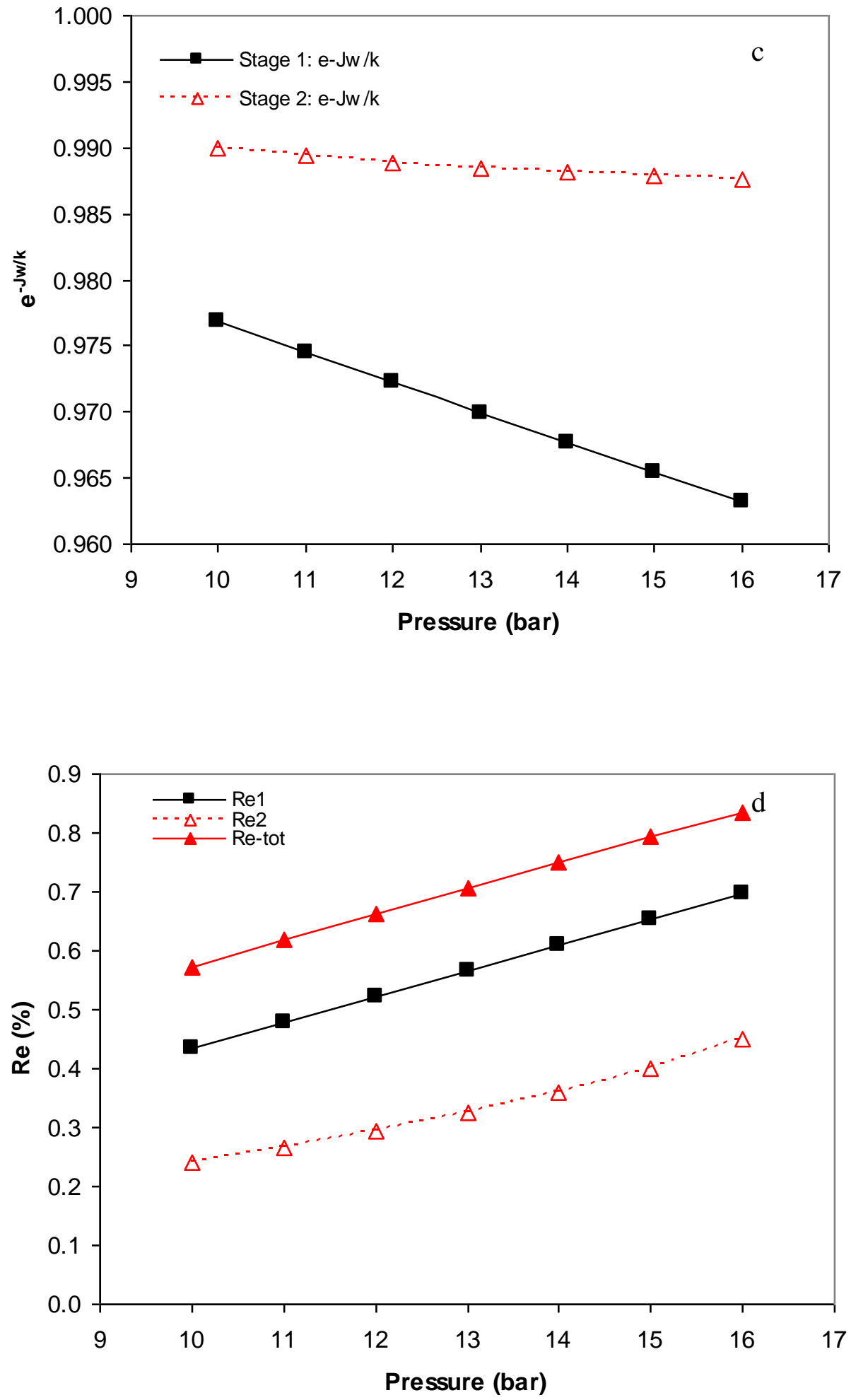


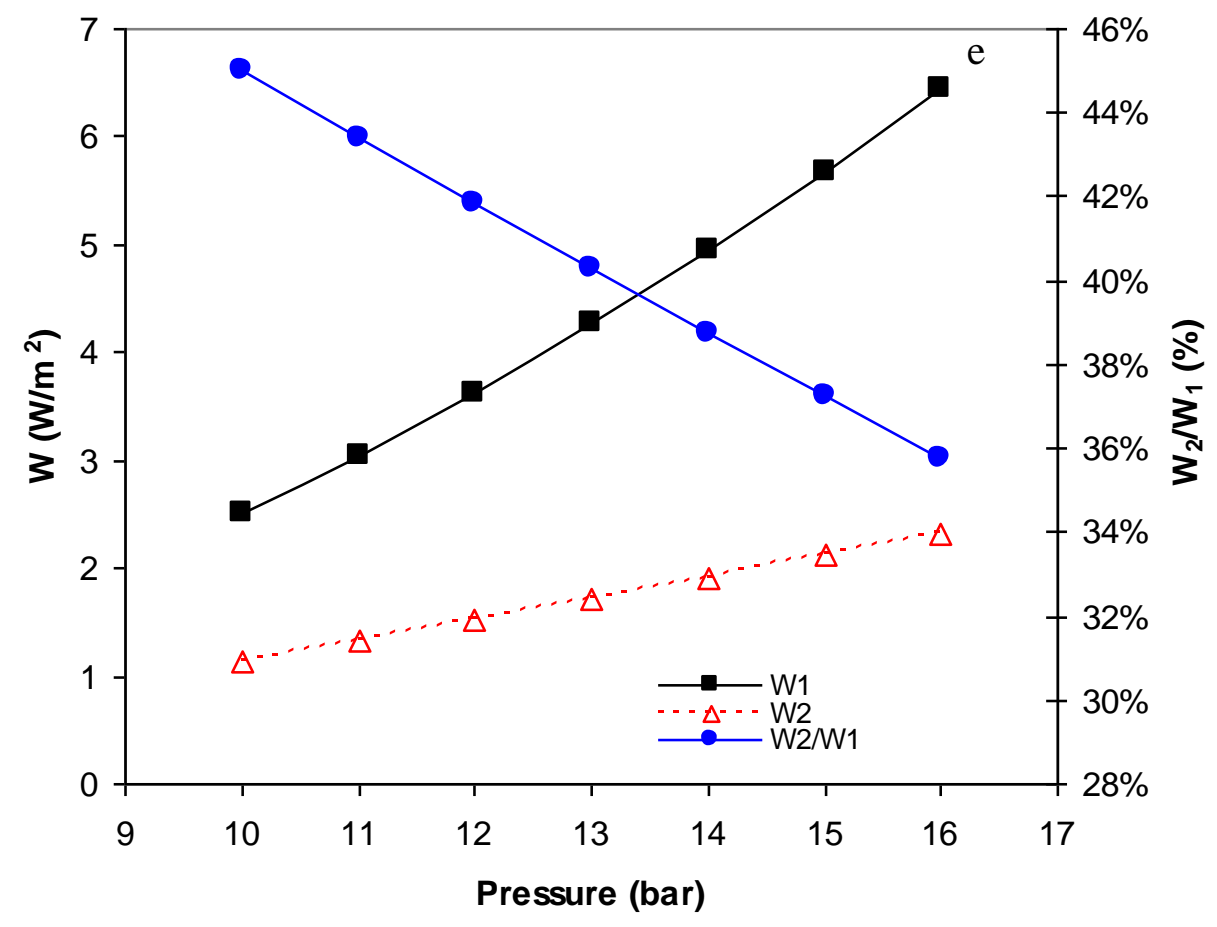

585

Figure 5: Impact of draw solution pressure on the single and DSPRO performance a) effect on the water flux and draw solution concentration b) effect of inlet and outlet concentration of DS of single and dual stage CLPRO c) effect on dilutive concentration polarization d) effect on the recovery rate of single and dual stage CLPRO e) effect on power density

The effect of the DS flow rate on the performance of CLPRO process was evaluated at a draw solution pressure of 16 bar and a membrane area of $300 \mathrm{~m}^{2}$ [Figure 6]. The simulation results revealed that the $J_{w 1}$ remained constant, about $11.6 \mathrm{~L} / \mathrm{m}^{2} \mathrm{~h}$, despite the increase in the DS flow rate from $2000 \mathrm{~L} / \mathrm{h}$ to $5000 \mathrm{~L} / \mathrm{h}$ [Figure 6a]. Previous studies demonstrated that the water flux increases with the increase of the DS flow rate, $Q_{D i 1}$, due to the higher bulk osmotic pressure of the DS [30,37]. At the present study, $C_{D i 1}$ and $\pi_{D i 1}$ decreased with the increase in the $Q_{D i 1} ; C_{D i 1}$, and $\pi_{D i 1}$ were decreased to maintain a constant $J_{w 1}$ across the PRO membrane [Figure 6a and 6b]. As such, the concentration of draw solution can be decreased at high flow rates; this operating condition would reduce the effect of CP but on the expense of slightly higher pumping energy.

For the second stage, the increase of $Q_{D i 1}$ resulted in an increase of $J_{w 2}$ [Figure $6 a]$. This was attributed to the increase of the concentration and osmotic pressure of the DS in the second stage of DSPRO [Figure $6 \mathrm{~b}$ ]. $J_{w 2}$ was $1.6 \mathrm{~L} / \mathrm{m}^{2} \mathrm{~h}$ and $4.2 \mathrm{~L} / \mathrm{m}^{2} \mathrm{~h}$ at $2500 \mathrm{~L} / \mathrm{h}$ and $5000 \mathrm{~L} / \mathrm{h} Q_{D i 1}$ respectively; the corresponding $C_{D i 2}$ for $2500 \mathrm{~L} / \mathrm{h}$ and $5000 \mathrm{~L} / \mathrm{h} Q_{D i 1}$ was $0.42 \mathrm{~mol} / \mathrm{L}$ and $0.52 \mathrm{~mol} / \mathrm{L}$, respectively [Figure 6b]. $e^{\frac{-J_{w}}{k}}$ of the first stage of the DSPRO remained unaffected by $Q_{D i 1}$ 
611 change indicating a constant ECP, whereas $J_{w 2}$ increased with the increase of

$612 Q_{D i 1}$ and it resulted in a higher $e^{\frac{-J_{w}}{k}}$ effect at $5000 \mathrm{~L} / \mathrm{h} Q_{D i 1}$ [Figure 6c]. For the 613 second stage of the DSPRO process, the outlet concentration of DS, $C_{D o 2}$, 614 increased from $0.39 \mathrm{~mol} / \mathrm{L}$ to $0.42 \mathrm{~mol} / \mathrm{L}$ due to the increase of $Q_{D i 1}$ from $2500 \mathrm{~L} / \mathrm{h}$ 615 to $5000 \mathrm{~L} / \mathrm{h}$ [Figure $6 \mathrm{~b}$ ].

616

For the first stage, $\mathrm{Re}_{1}$ remained constant at $70 \%$ with the increase in $Q_{D i 1}$ 618 [Figure 6d]. However, the recovery rate of the second stage, $R_{2}$, increased from $61914 \%$ to $51 \%$ as a result of the increase in $Q_{D i 1}$ from $2500 \mathrm{~L} / \mathrm{h}$ to $5000 \mathrm{~L} / \mathrm{h}$ [Figure $6206 \mathrm{~d}]$. This was attributed to the higher permeation flow in the second stage of the DSPRO. Re-tot of the DSPRO process also increased with the increase of $Q_{D i 1}$ and it reached $85 \%$ at a $Q_{D i 1}$ of $4500 \mathrm{~L} / \mathrm{h}$. Finally, the power density of the first and second stage of the DSPRO process is illustrated in [Figure 6e]. $W_{1}$ was unaffected by the variation of $Q_{D i 1}$ from $2500 \mathrm{~L} / \mathrm{m}^{2}$ to $5000 \mathrm{~L} / \mathrm{m}^{2}$. On the contrary, $W_{2}$ increased from $0.9 \mathrm{~W} / \mathrm{m}^{2}$ to $2.3 \mathrm{~W} / \mathrm{m}^{2}$ due to the increase in $Q_{D i 1}$ from 2500 $\mathrm{L} / \mathrm{m}^{2}$ to $5000 \mathrm{~L} / \mathrm{m}^{2}$. $W_{2}$ was about $20 \%$ to $70 \%$ of $W_{1}$ at $2500 \mathrm{~L} / \mathrm{m}^{2}$ and $5000 \mathrm{~L} / \mathrm{m}^{2}$ $Q_{D i 1}$ respectively. As such, $W_{2}$ was almost negligible at a $Q_{D i 1}$ of $2000 \mathrm{~L} / \mathrm{m}^{2}$. This suggests that reducing $Q_{D i 1}$ can significantly affect the performance of the second stage of the CLPRO process and hence it should be avoided. As such, a $Q_{D i 1}$ of $5000 \mathrm{~L} / \mathrm{m} 2$ was selected due to the higher performance of the DSPRO process.

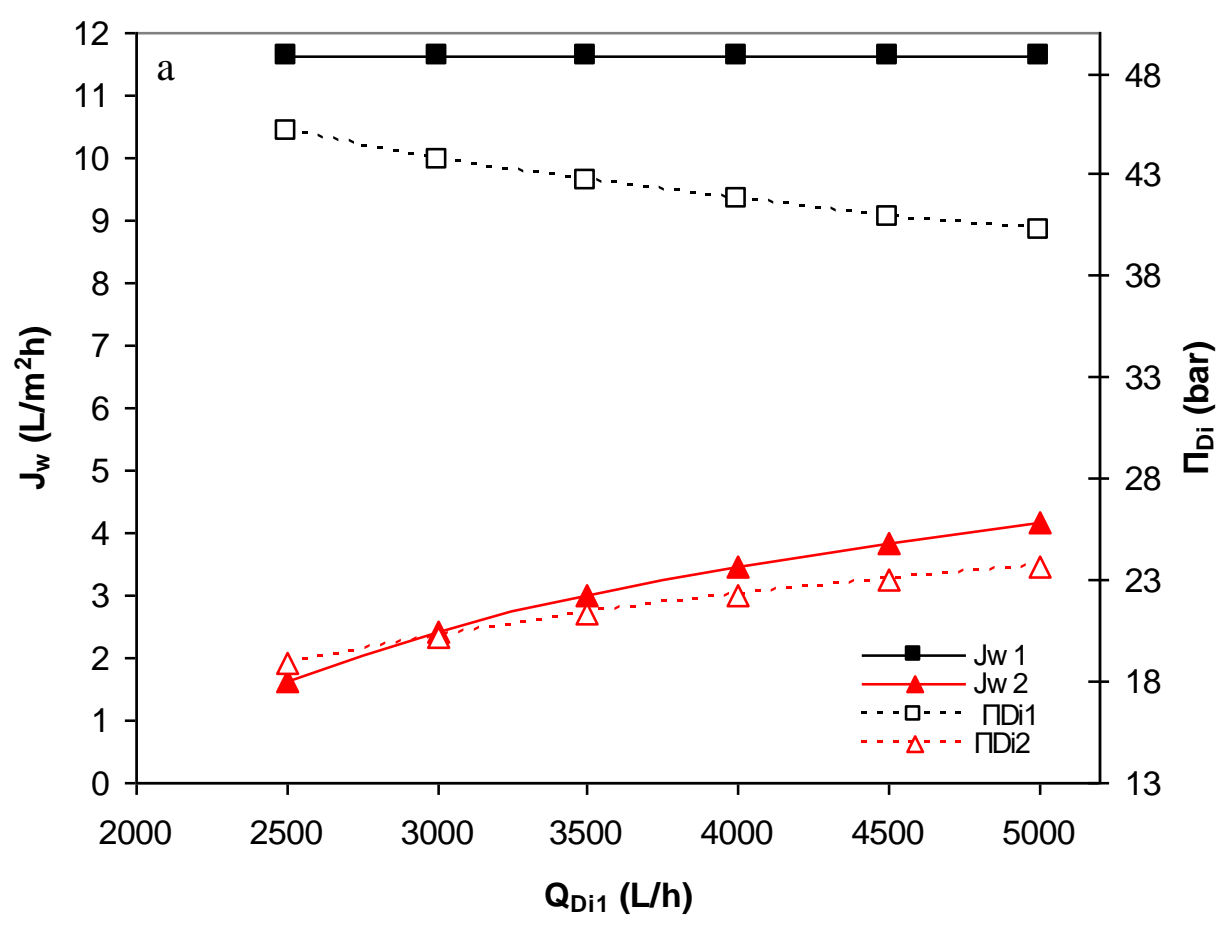

634

635 


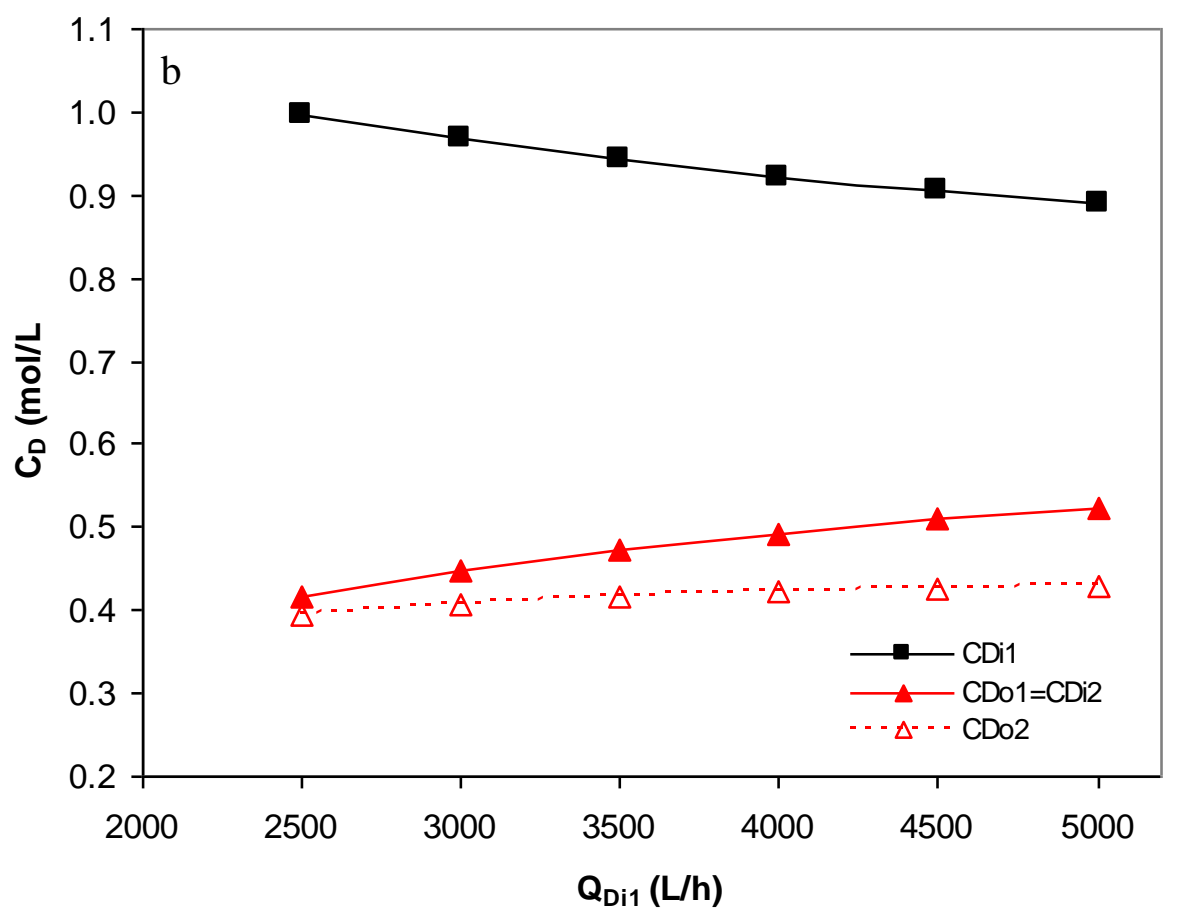

637

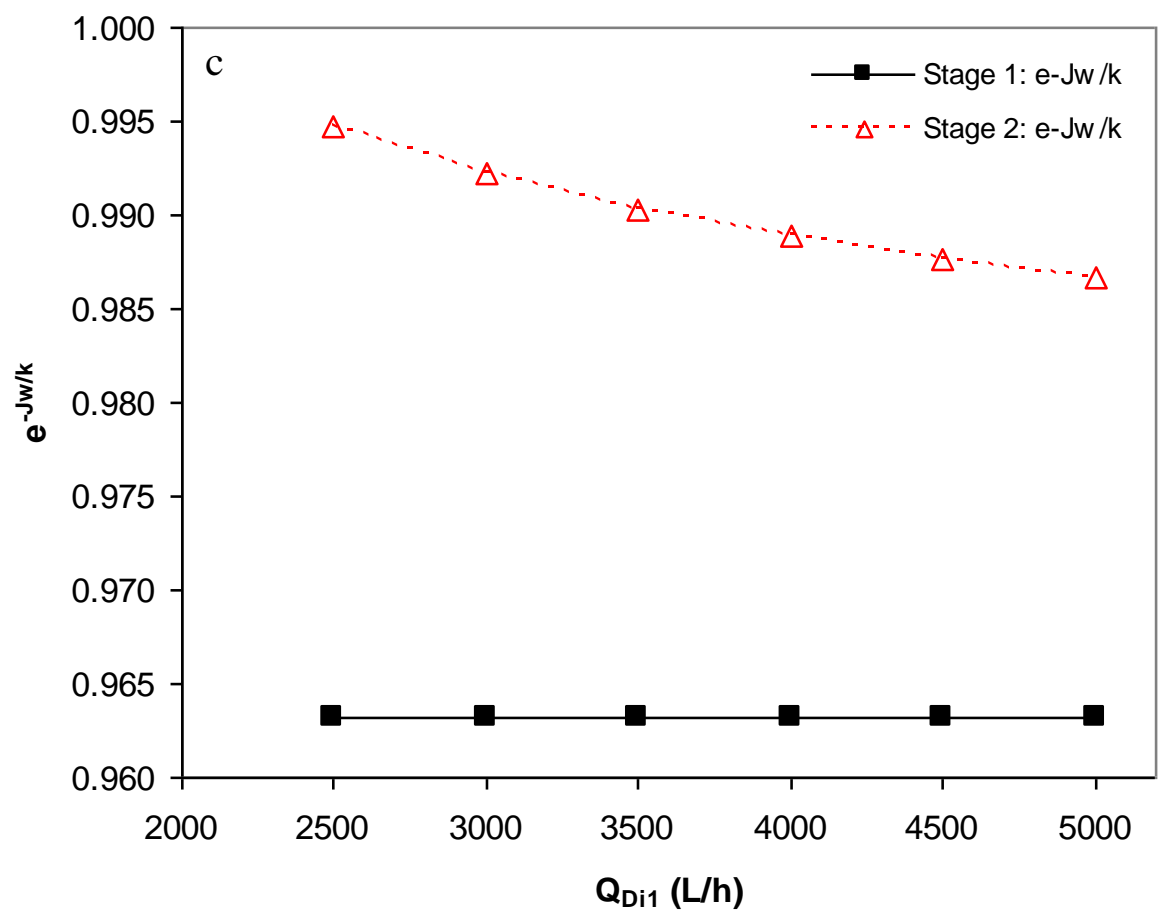

638

639

640 
641

642

643

644

645

646

647 648
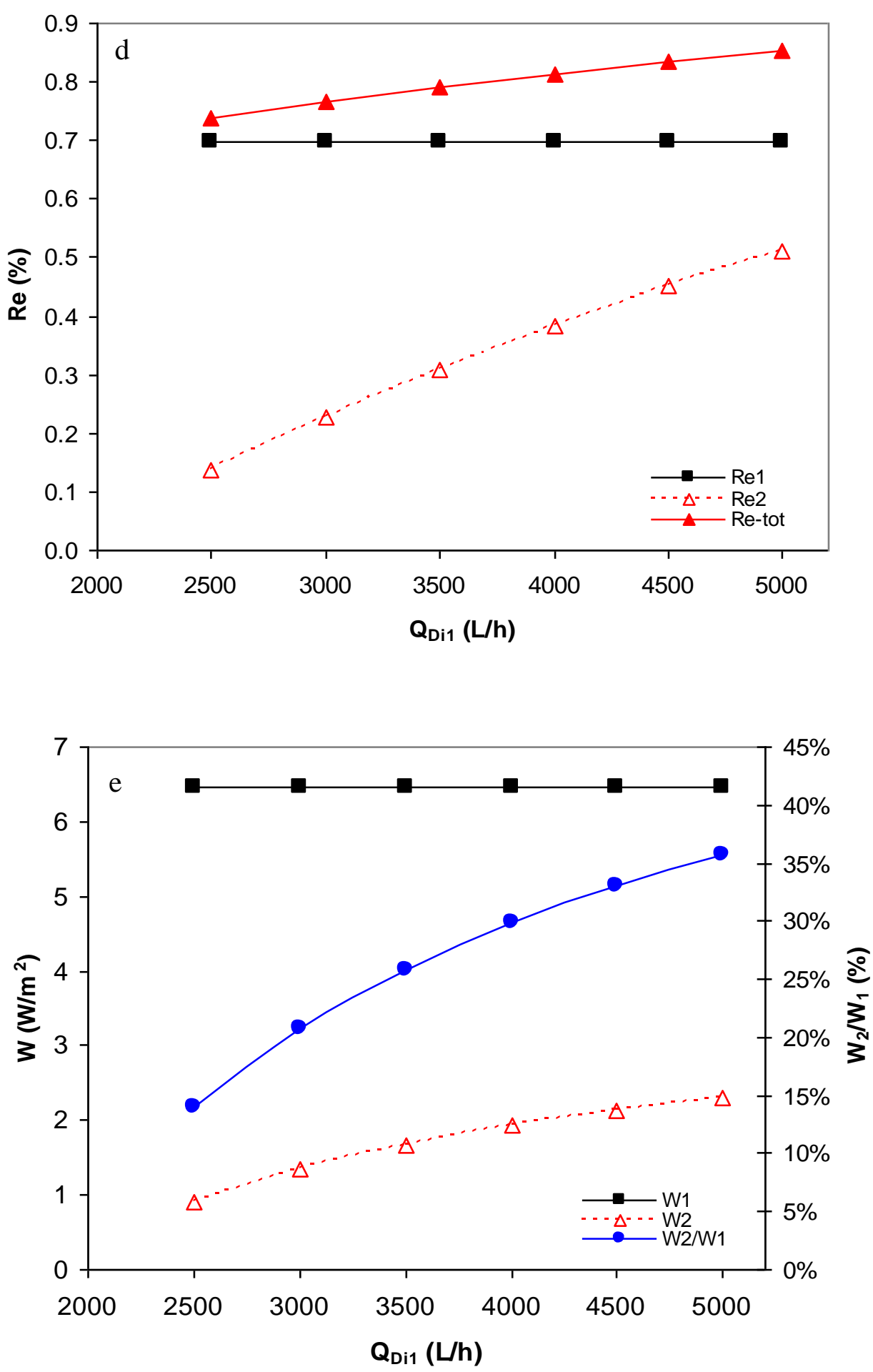

Figure 6: Impact of draw solution flow rate on the performance of single and dual stage PRO process a) effect on the water flux and DS concentration b) effect of inlet and outlet concentration of DS of single and dual stage CLPRO c) effect on dilutive concentration polarization d) recovery rate effect on single and dual stage CLPRO e) effect on power density 
650 The results showed that dual stage CLPRO performed better than the single 651 stage CLPRO at all operating conditions. But it should be observed that the draw solution pressure and the DS flow rate were the most influential parameters in the first and second stage of the DSPRO, respectively, whereas the membrane area had low impact on the process performance. In practical terms, the pressure of the draw solution would be fixed at $\Delta \pi / 2$ in order to increase the power generation of the first stage while the flow rate of the DS should be increased to enhance the performance of the second stage of the DSPRO process. Furthermore, the concentration of draw solution can be decreased at high draw solution flow rates. The percentage of $W_{1}$ and $W_{2}$ variation with the membrane area, draw solution pressure and DS flow rate are presented in Table 3 . The values shown in column 6 and 7 were calculated as the percentage difference with the upper value of each stage. In general, the draw solution pressure is the most influential parameter in the first stage followed by draw solution flow rate and membrane area, respectively. For example, $61 \%$ increase in $W_{1}$ was achieved due to the increase of draw solution pressure from 10 bar to 16 bar. However, the concentration of draw solution should be increased at high draw solution pressures to maintain enough osmotic potential across the membrane. For the second stage of the DSPRO, DS flow rate was the most influential parameter followed by the draw solution pressure and membrane area, respectively. About the $61 \%$ increase of $W_{2}$ occurred due to the increase of the DS flow rate from $2500 \mathrm{~L} / \mathrm{h}$ to $5000 \mathrm{~L} / \mathrm{h}$.

It should be mentioned that the model used for water flux prediction throughout this study was developed on a flat sheet membrane unit. Therefore, it roughly estimated water flux in a full scale PRO module since it did not take into account the impact of water flux along the PRO module, pressure drop, and residence time effect on the water flux. In such case the results of this study should be cautiously dealt with to avoid major errors and experimental work is highly recommended to validate the system performance. Also, the simulation results showed that $W_{1}$ was 2 to 3 times more than $W_{2}$ indicating that the DSPRO efficiency is mainly based on the performance of the first stage of the DSPRO. These model results show the influence of membrane area, draw solution pressure and draw solution flow rate on the power density of the CLPRO process, thus they can be used in the design of the single and dual stage CLPRO plant and the system optimization to reduce the capital and operating costs. 
694

695

696

697

698

699

700

701

702

703

704

705

706

707

708

709

710

711

712

713

714

715

716

717

Table 3: Impact of operating parameters on the inlet concentration of draw solution to the single and dual stage CLPRO process and power density of single and dual stage CLPRO process

\begin{tabular}{|c|c|c|c|c|c|c|}
\hline $\begin{array}{c}\text { Parameter } \\
A\left(m^{2}\right)\end{array}$ & $\begin{array}{c}C_{D i 1} \\
(\mathrm{~mol} / \mathrm{L})\end{array}$ & $\begin{array}{c}C_{D i 2} \\
(\mathrm{~mol} / \mathrm{L})\end{array}$ & $\begin{array}{c}W_{1} \\
\left(\mathrm{~W} / \mathrm{m}^{2}\right)\end{array}$ & $\begin{array}{c}W_{2} \\
\left(\mathbf{W} / \mathrm{m}^{2}\right)\end{array}$ & $\begin{array}{c}\% \text { Diff } W_{1} \\
\text { stage } 1\end{array}$ & $\begin{array}{c}\% \text { Diff } W_{2} \\
\text { stage } 2\end{array}$ \\
\hline 200 & 0.84 & 0.58 & 6.20 & 2.84 & $-3.9 \%$ & $0.0 \%$ \\
\hline 220 & 0.85 & 0.57 & 6.27 & 2.74 & $-2.9 \%$ & $3.7 \%$ \\
\hline 240 & 0.86 & 0.56 & 6.33 & 2.63 & $-2.0 \%$ & $7.5 \%$ \\
\hline 260 & 0.87 & 0.54 & 6.38 & 2.52 & $-1.2 \%$ & $11.3 \%$ \\
\hline 280 & 0.88 & 0.53 & 6.42 & 2.42 & $-0.6 \%$ & $15.1 \%$ \\
\hline 300 & 0.89 & 0.52 & 6.46 & 2.31 & $0.0 \%$ & $18.9 \%$ \\
\hline \multicolumn{7}{|l|}{$\mathbf{P}$ (bar) } \\
\hline 10 & 0.52 & 0.36 & 2.52 & 1.13 & $-61.0 \%$ & $-50.8 \%$ \\
\hline 11 & 0.58 & 0.39 & 3.05 & 1.33 & $-52.7 \%$ & $-42.6 \%$ \\
\hline 12 & 0.64 & 0.42 & 3.63 & 1.52 & $-43.8 \%$ & $-34.1 \%$ \\
\hline 13 & 0.70 & 0.45 & 4.26 & 1.72 & $-34.0 \%$ & $-25.6 \%$ \\
\hline 14 & 0.76 & 0.47 & 4.94 & 1.92 & $-23.4 \%$ & $-17.0 \%$ \\
\hline 15 & 0.83 & 0.50 & 5.67 & 2.11 & $-12.1 \%$ & $-8.4 \%$ \\
\hline 16 & 0.89 & 0.52 & 6.46 & 2.31 & $0.0 \%$ & $0.0 \%$ \\
\hline \multicolumn{7}{|l|}{$Q_{D i 1}(\mathrm{~L} / \mathrm{h})$} \\
\hline 2500 & 1.00 & 0.42 & 6.46 & 0.90 & - & $-60.9 \%$ \\
\hline 3000 & 0.97 & 0.45 & 6.46 & 1.34 & - & $-42.0 \%$ \\
\hline 3500 & 0.94 & 0.47 & 6.46 & 1.67 & - & $-27.6 \%$ \\
\hline 4000 & 0.92 & 0.49 & 6.46 & 1.93 & - & $-16.4 \%$ \\
\hline 4500 & 0.90 & 0.51 & 6.46 & 2.14 & - & $-7.4 \%$ \\
\hline 5000 & 0.89 & 0.52 & 6.46 & 2.31 & - & $0.0 \%$ \\
\hline
\end{tabular}

\subsection{MED regeneration system}

The MED model described in Section 2.3 was considered for the draw solution regeneration. The effect of PRO membrane area on the MED performance was evaluated using 16 bar as the draw solution pressure and a draw solution flow rate of $5000 \mathrm{~L} / \mathrm{h}$ [Figure 7]. The recovery rate of the MED process increased with the increase of the PRO membrane area [Figure 7a]. At a membrane area of 300 $\mathrm{m}^{2}$, the maximum recovery rate of single stage CLPRO, $\mathrm{Re}_{1}$, was $46.5 \%$ which is $8 \%$ lower than the recovery rate of the dual stage CLPRO, Re2. The TBT of the MED plant was $73^{\circ} \mathrm{C}$ at $\operatorname{Re}_{1}$ of $46.5 \%$, and increased to $76{ }^{\circ} \mathrm{C}$ at $\operatorname{Re}_{2}$ of $50.2 \%$ [Figure 7a]. For a single stage PRO process, TBT increased from $67^{\circ} \mathrm{C}$ to $73^{\circ} \mathrm{C}$ due to the increase of $R_{1}$ from $35.8 \%$ to $46.5 \%$, respectively. For a dual stage CLPRO process, TBT was $71{ }^{\circ} \mathrm{C}$ and $76{ }^{\circ} \mathrm{C}$ at $\operatorname{Re} 240.7 \%$ and $50.2 \%$, respectively. Therefore, the TBT for a single stage CLPRO was $4 \%$ and $6 \%$ lower than that for a dual stage CLPRO process at a draw solution pressure of 10 bar and 16 bar, respectively. Dual stage CLPRO process, in practice, requires higher TBT than single stage PRO due to the higher recovery rates achieved by the former process. The Specific Thermal Consumption (STC) represents the thermal 
power required for saline water purification. Figure $8 \mathrm{~b}$ shows the $\mathrm{STC}_{\mathrm{TC}}$ for the regeneration of DS in a single and dual stage CLPRO. STC for a single stage was higher than that for a dual stage CLPRO process [Figure 7b]. STc for the single stage CLPRO process decreased from $67 \mathrm{kWh} / \mathrm{m}^{3}$ at $200 \mathrm{~m}^{2}$ to $51 \mathrm{kWh} / \mathrm{m}^{3}$ at $300 \mathrm{~m}^{2}$. For the dual stage CLPRO process, STc decreased from $61 \mathrm{kWh} / \mathrm{m}^{3}$ at $200 \mathrm{~m}^{2}$ to $48 \mathrm{kWh} / \mathrm{m}^{3}$ at $300 \mathrm{~m}^{2}$. The results reveal that STc for the dual stage CLPRO was lower than that for the single stage. However, that was on the expense of the higher heat transfer area, Aeff, required for the dual stage CLPRO process [Figure $7 \mathrm{~b}$ ], which is disadvantageous due to the fact that the increase of the A Aff lead to a rise in the capital cost of the MED process. Results in Table 4 show the number of effects of MED plant suggested for draw solution regeneration. Obviously, the number of effects of the MED plant for the regeneration of DS from a dual stage CLPRO was higher than that for the single stage CLPRO process. This also suggests that the MED capital cost for draw solution regeneration would be higher in the case of a dual stage CLPRO process. $P_{W-M E D}$ represents the electric energy required for the draw solution regeneration by the MED process, which is considered about $1.2 \mathrm{kWh} / \mathrm{m}^{3}$ [39]. The ratio of $P_{W-P R O} P_{W-M E D}$ was $103 \%$ and $127 \%$ for the single and dual stage CLPRO, respectively [Figure $7 \mathrm{c}$ ]. $P_{W-P R O} / P_{W-M E D}$ ratio over hundred was an indicative of a positive power generation; i.e. power generation by CLPRO is higher than the power consumption for the regeneration of DS. Results show that the $P_{W-P R O} / P_{W-M E D}$ ratio increased to $162 \%$ and $186 \%$ for the single and dual stage CLPRO, respectively. Apparently, the energy efficiency of the dual stage CLPRO was higher than that of the single stage, which will potentially pay off for the higher capital cost of the dual stage CLPRO system. 


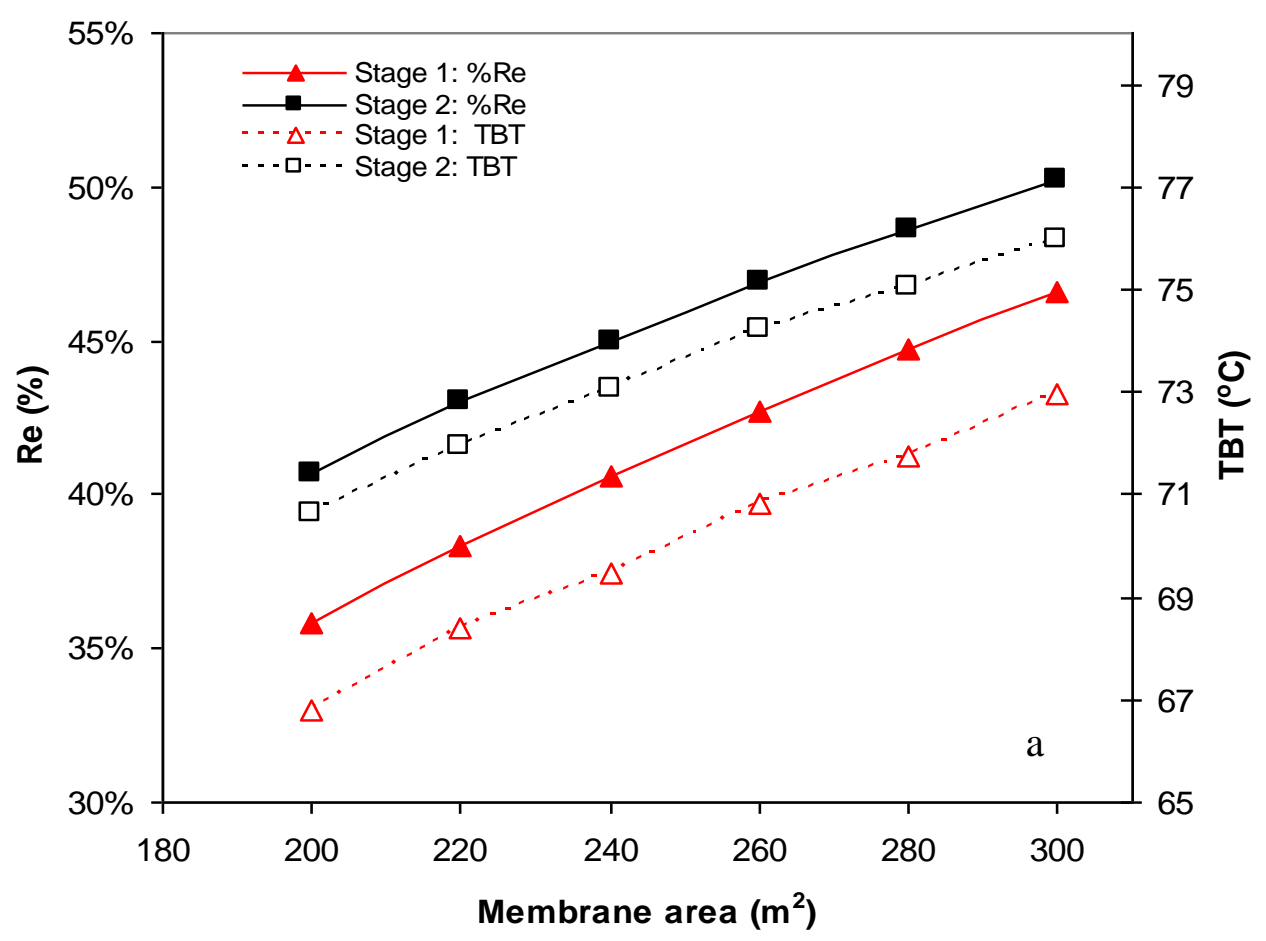

744

745

746

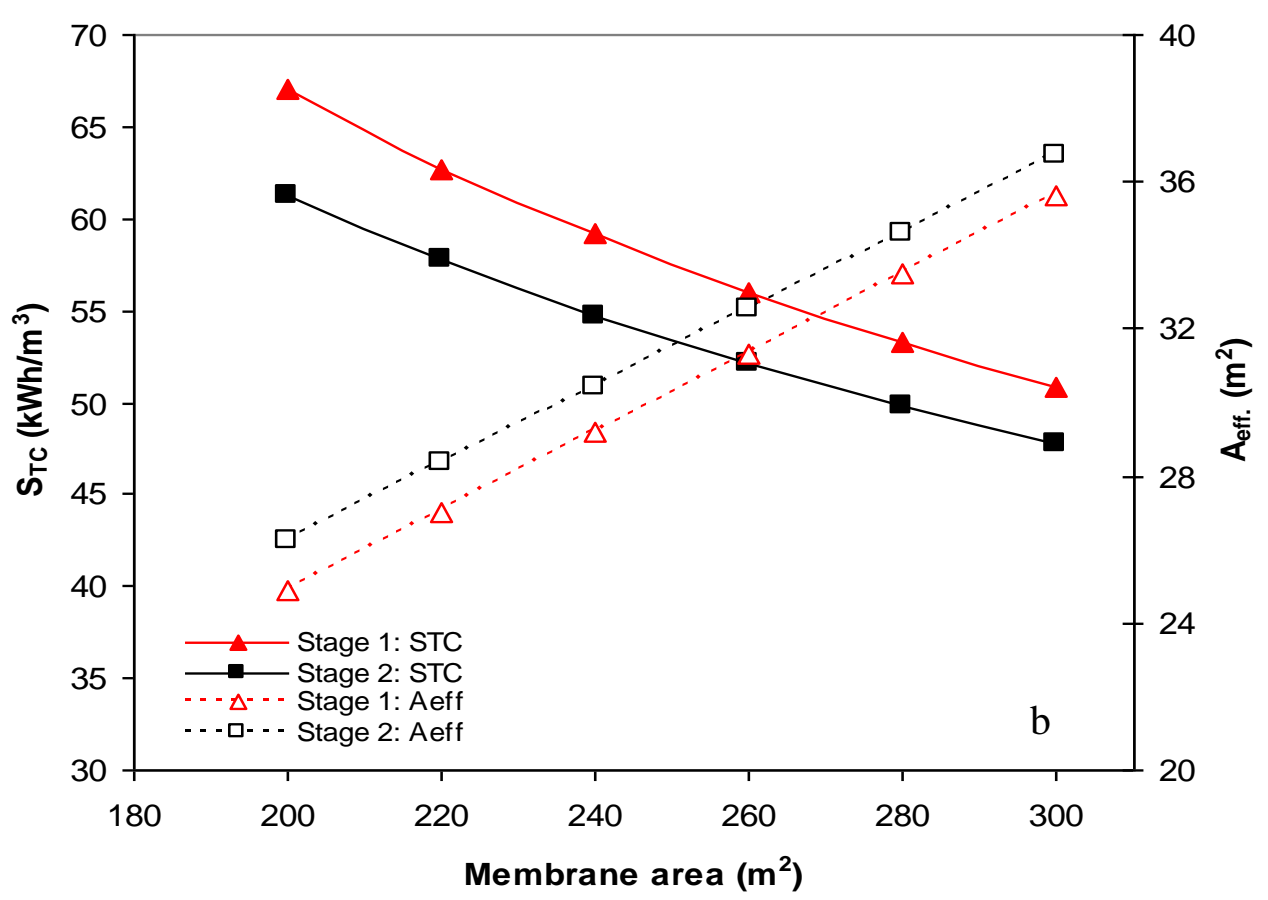




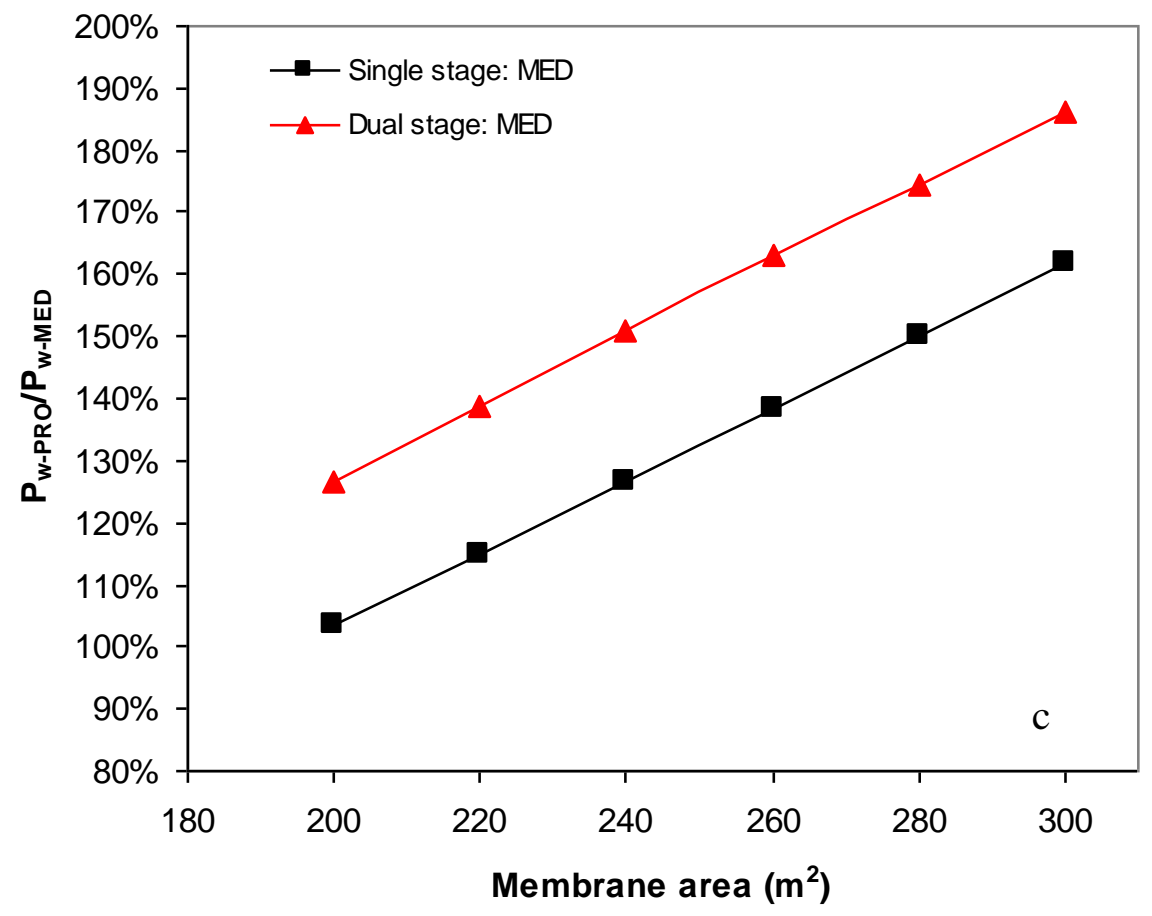

The impact of the draw solution pressure on the performance of the MED regeneration plant was evaluated using a membrane area of $300 \mathrm{~m}^{2}$ and a $Q_{D i 1}$ of $5000 \mathrm{~L} / \mathrm{h}$ [Figure 8]. $\mathrm{Re}_{1}$ and $\mathrm{Re}_{2}$ increased with the increase in the PRO membrane area. However, $\mathrm{Re}_{2}$ was $16 \%$ higher than $\mathrm{Re}_{1}$ at a draw solution pressure of 10 bar. The TBT required for the DS regeneration in a dual stage CLPRO was higher than that required in a single stage CLPRO [Figure 8a]. Furthermore, at a draw solution pressure of 16 bar, $R_{2}$ was $10 \%$ higher than $\mathrm{Re}_{1}$ whereas the TBT required for the DS regeneration in the dual stage CLPRO was only $4 \%$ higher than that required for the DS regeneration in the single stage CLPRO. The TBT required for the regeneration of DS was $69^{\circ} \mathrm{C}$ and $72^{\circ} \mathrm{C}$ for the single and the dual stage CLPRO processes, respectively [Figure 8a]. These TBT's were almost within the range of operating temperatures required in the thermal energy source for commercial MED plants.

The STc for the draw solution regeneration of the single stage CLPRO process was $77 \mathrm{kWh} / \mathrm{m}^{3}$ and $55 \mathrm{kWh} / \mathrm{m}^{3}$ at a draw solution pressure of 10 bar and $16 \mathrm{bar}$, respectively [Figure $8 \mathrm{~b}$ ]. This was higher than the $\mathrm{S}_{\mathrm{TC}}$ required for the draw solution regeneration of the dual stage CLPRO process: $69 \mathrm{kWh} / \mathrm{m}^{3}$ and 51 $\mathrm{kWh} / \mathrm{m}^{3}$ at 10 bar and 16 bar, respectively. Furthermore, the dual stage required slightly more Aeff than the single stage CLPRO process. It should be noticed that 
the difference of $A_{\text {eff }}$ between the single stage and the dual stage CLPRO process decreased at a draw solution pressure of 16 bar [Figure $8 \mathrm{c}$ ]. Table 4 shows the number of effects of the MED plant, in which it can be seen that between 11 and 15 effects were required for the regeneration of DS in the single stage CLPRO whereas between 12 and 18 effects were required in the MED for the regeneration of DS in the dual stage CLPRO.

The results also showed a $P_{W-P R O} / P_{W-M E D}$ ratio ration over a hundred percent, indicating a positive power generation, i.e. power generation by the CLPRO was higher than the electric power consumption by the MED process for regenerating the DS [Figure 8c]. For the single and dual stage CLRPO, the PW-PRO/PW-MED ratio increased with the increase of the draw solution pressure from 10 bar to 16 bar. At a draw solution pressure of 16 bar, the ratio of $P_{W-P R O} / P_{W-M E D}$ was $132 \%$ and $157 \%$ for the single and dual stage CLPRO process, respectively. Indeed, the dual stage CLPRO process was more energy efficient than the single stage process. It should be noted that the difference of the $P_{W-P R O} / P_{W-M E D}$ ratio between the single and dual stage CLPRO process increased with the increase in the feed pressure. Thus, the efficiency of the dual stage CLPRO process increases with the increase in the feed pressure.

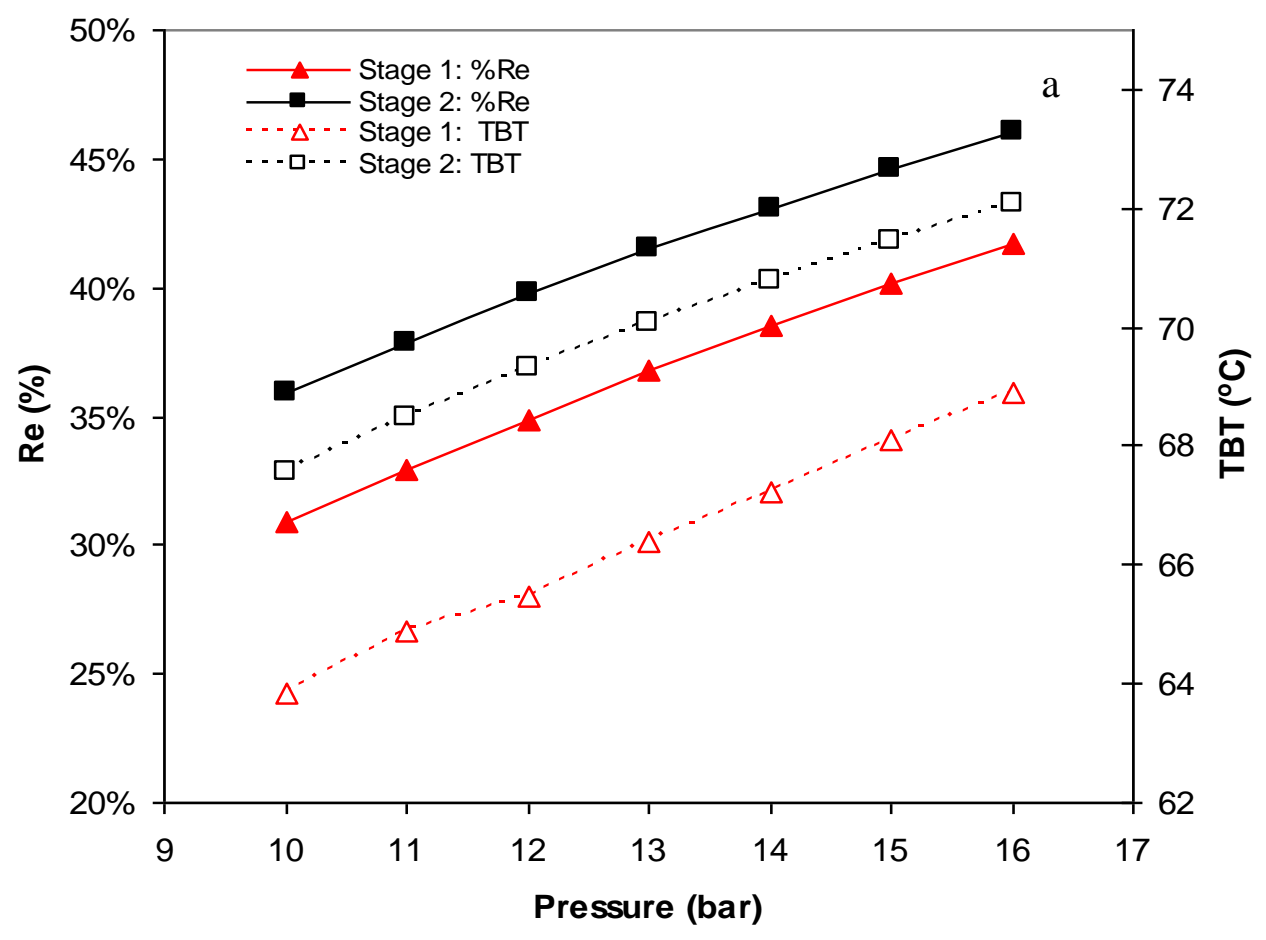




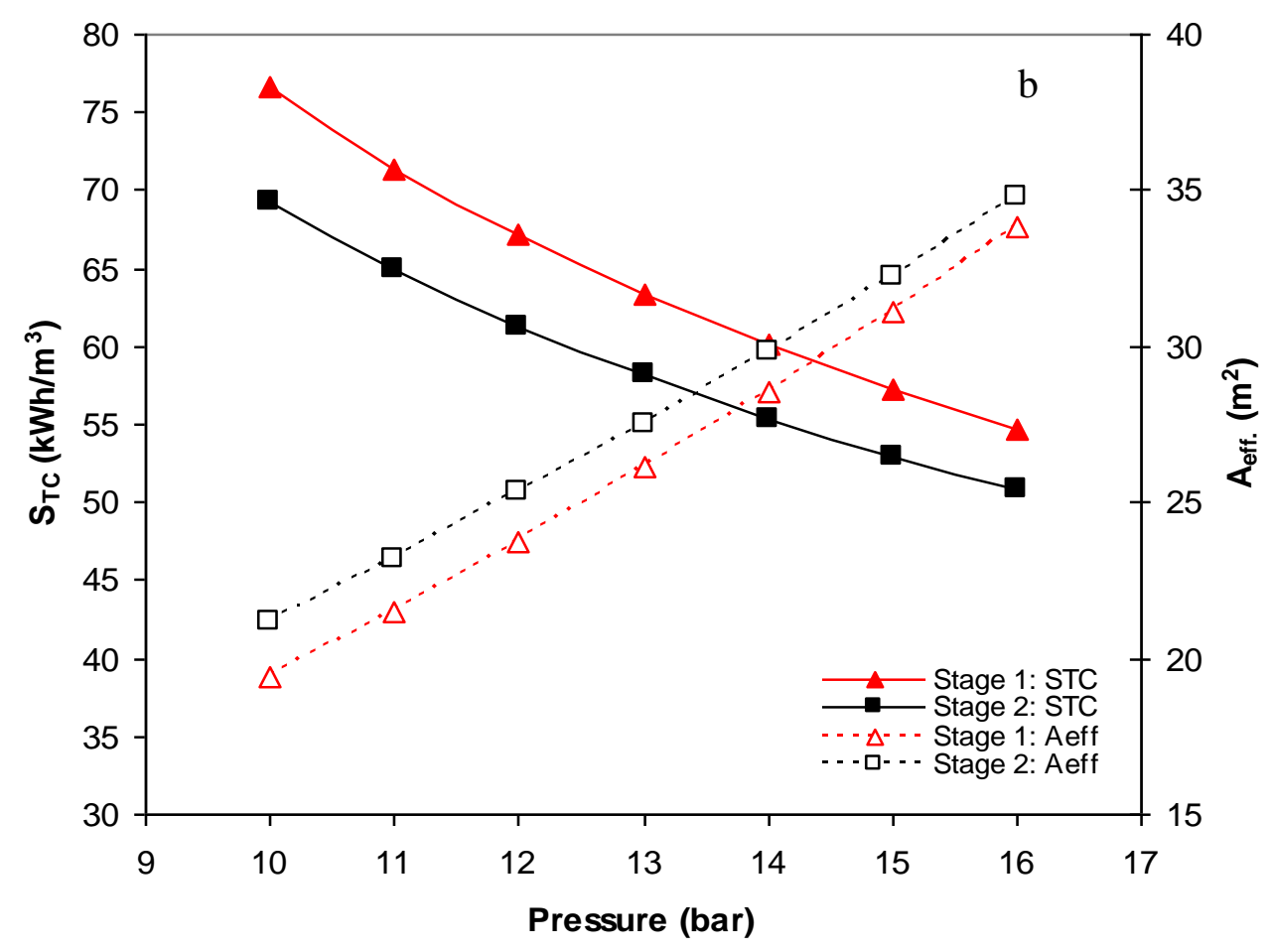

799

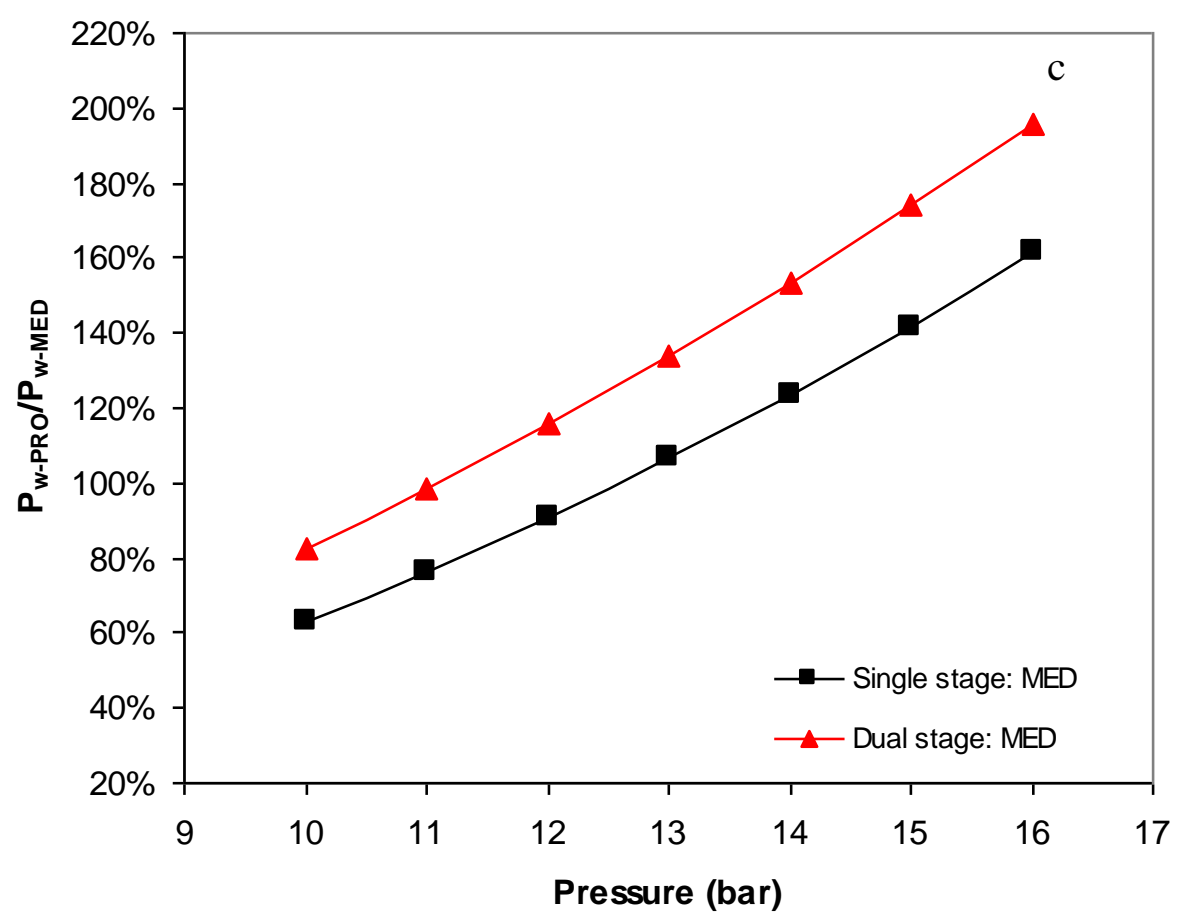

800

801

802

Figure 8: Impact of CLPRO draw solution pressure on the specifications of MED

803 thermal plant a) effect on recovery rate and TBT b) effect on specific thermal

804 consumption and heat transfer area c) effect of membrane area on the energy

805 efficiency 
808 Figure 9 shows the impact of the draw solution flow rate, $Q_{\text {Di1 }}$, on the performance of the CLPRO process at a draw solution pressure of 16 bar and a PRO membrane area of $300 \mathrm{~m}^{2}$. $\mathrm{Re}_{1}$ and $\mathrm{Re}_{2}$ decreased with the increase in $Q_{D i 1}$ from $2500 \mathrm{~L} / \mathrm{h}$ to $5000 \mathrm{~L} / \mathrm{h}$. However, $\mathrm{Re}_{2}$ was always higher than $\mathrm{Re}_{1}$ but the difference between $\mathrm{Re}_{1}$ and $\mathrm{Re}_{2}$ increased with the increase in $Q_{D i 1}$ [Figure 9a]. Furthermore, the TBT of the MED regeneration process for the single stage CLPRO process was unaffected by the increase of $Q_{D i 1}$. However, this was on the expense of higher STC at high $Q_{\text {Di1 }}$ [Table 4]. In the case of the dual stage CLPRO process, the TBT of the MED was very sensitive to the change of $Q_{D i 1}$. In general, the TBT of the MED unit treating a diluted draw solution from a single stage CLPRO process was lower than that from a dual stage CLPRO process. At a draw solution pressure of 16 bar, the TBT of the MED plant was $72^{\circ} \mathrm{C}$ and 76 ${ }^{\circ} \mathrm{C}$ for a single and dual stage CLPRO, respectively. These TBTs were slightly higher than that normally used in the commercial MED plants. The results also revealed that the STC for the DS regeneration from the single stage CLPRO process was higher than that for the DS regeneration from the dual stage CLPRO [Figure 9b]. However, Aeff of the MED was higher for the dual stage CLPRO [Figure 9b] but the difference in Aeff between the single stage and the dual stage CLPRO process slightly decreased with the increase in the $Q_{D i 1}$. Thus, applying high draw solution flow rates would decrease the capital cost of the MED plant.

The ratio of $P_{W-P R O} P_{W-M E D}$ for a single stage CLPRO process remained constant at $161 \%$ despite the increase of $Q_{D i 1}$ [Figure 9c]. For the dual stage CLPRO, the ratio of $P_{W-P R O} / P_{W-M E D}$ was $171 \%$ at $2500 \mathrm{~L} / \mathrm{h}$ but increased to $195 \%$ at $5000 \mathrm{~L} / \mathrm{h}$ $Q_{\text {Di1. }}$ This suggests that dual stage CLRPO process was more energy efficient than the single stage CLPRO process especially at higher $Q_{D i 1}$. At $5000 \mathrm{~L} / \mathrm{h} Q_{D i 1}$, the ratio of $P_{W-P R O} / P_{W-M E D}$ for the dual stage CLPRO was $21 \%$ higher than that for the single stage CLPRO process. MED regeneration of the DS resulted in a positive PRO power generation assuming that the power consumption in the MED process was mainly electrical whereas thermal energy provided by a source of waste heat.

The dual stage CLPRO process is more energy efficient than the single stage CLPRO but it requires higher TBT and heat transfer area for the regeneration of the draw solution by the MED process. The range of TBT for the regeneration of DS was between $67^{\circ} \mathrm{C}$ and $75^{\circ} \mathrm{C}$ for the dual stage CLPRO which will not affect the operation cost of the MED plant if a free source of waste heat is available. Interestingly, the STC of MED for treatment of DS from the dual stage CLPRO was lower than that of MED for treatment of DS from the single stage CLPRO. This emphasizes the superiority of dual stage CLPRO process over the single stage CLPRO process. The results suggest that dual stage CLPRO coupling with the MED process can be a viable option for power generation from a salinity gradient resource. The system can be also used for energy storage. In this case, a source of thermal energy would be applied for the regeneration of draw and 
852 feed solution by the MED process. This energy can be recovered later on by 853 pairing the draw and feed solutions in the PRO process for power generation.

854

855

856

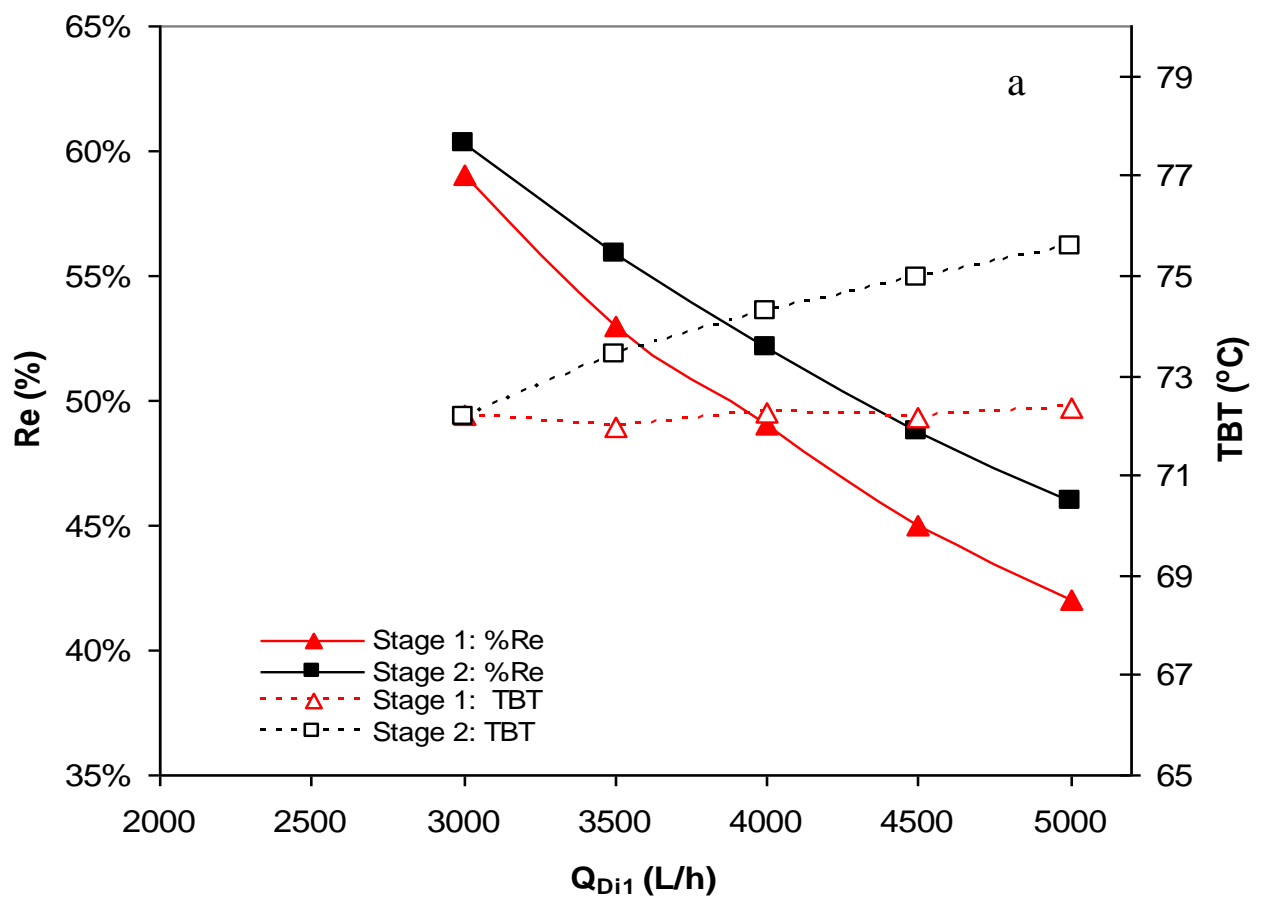




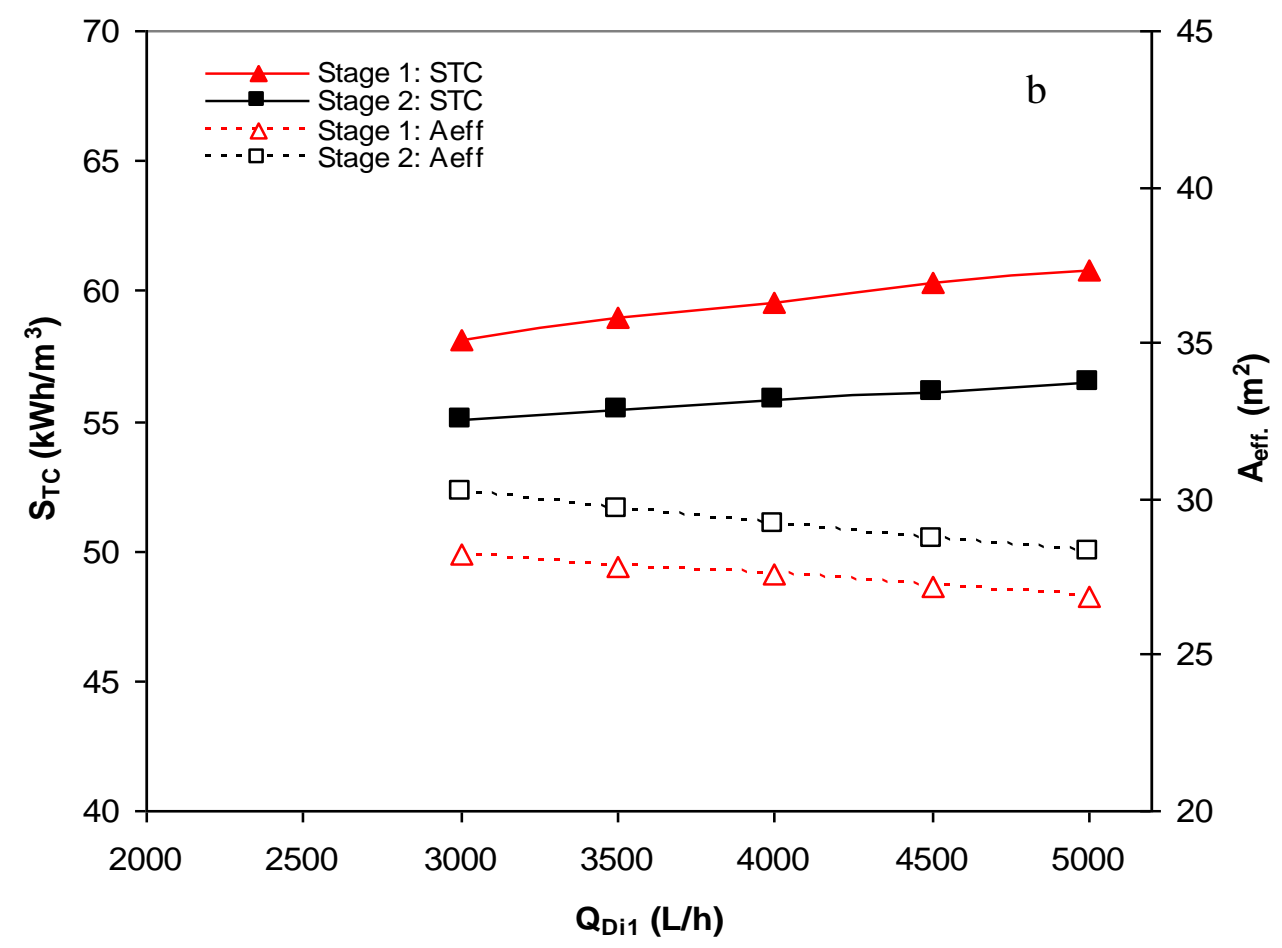

860

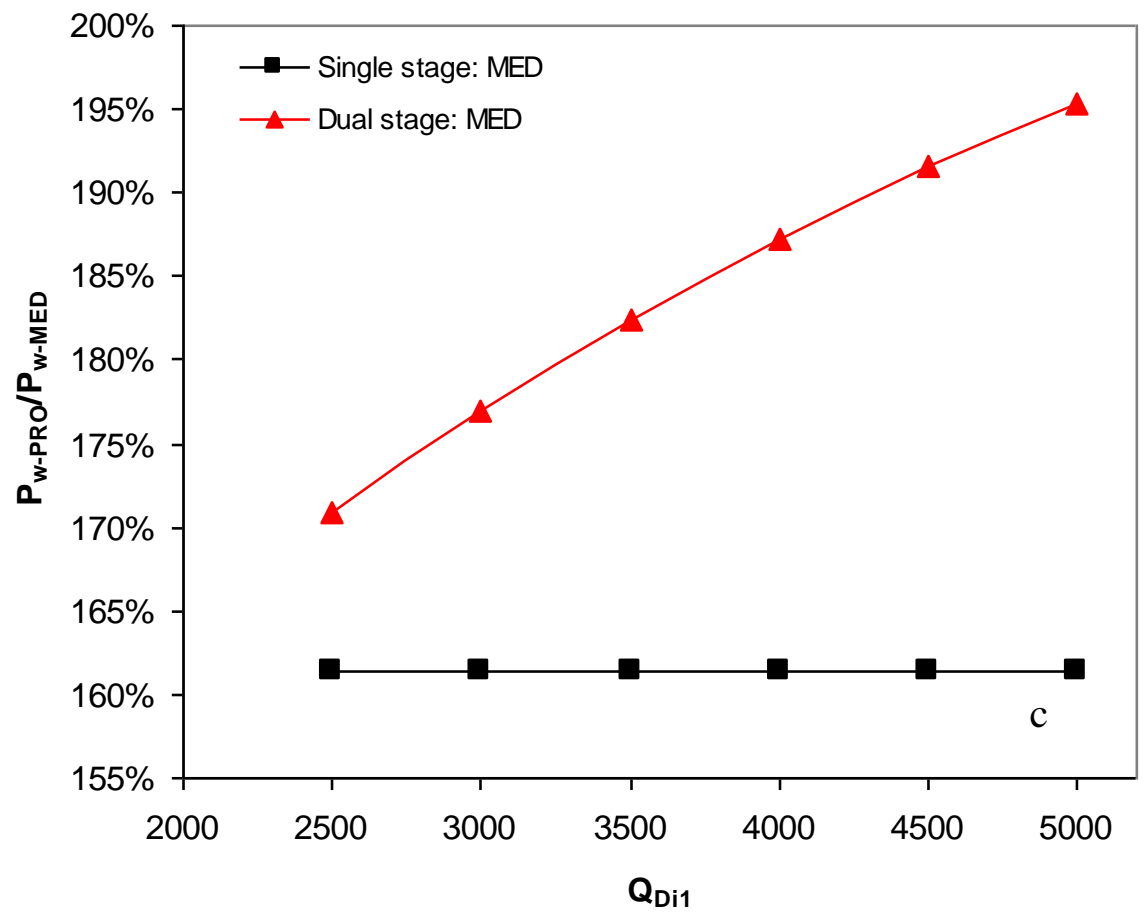

861

862

863

864

865
Figure 9: Effect of CLPRO DS flow rate on the specifications of MED thermal plant a) effect on recovery rate and TBT b) effect on specific thermal consumption and heat transfer area c) effect of membrane area on the energy efficiency of single and dual stage CLPRO 
866

867

868

869

870
871

872

873

874

875

876

877

878

879

880

881

882

883

884

885

886

887

888

889
Table 4: Impact of CLPRO operating parameters on the specific thermal consumption and number of effects of the single and dual stage CLPRO process

\begin{tabular}{|c|c|c|c|c|}
\hline \multirow{2}{*}{$\begin{array}{c}\text { Parameter } \\
\mathbf{A}\left(\mathbf{m}^{2}\right)\end{array}$} & \multicolumn{2}{|c|}{ Single stage CLPRO } & \multicolumn{2}{|c|}{ Dual stage CLPRO } \\
\hline & $\begin{array}{c}\text { STC } \\
\mathrm{kWh} / \mathrm{m}^{3}\end{array}$ & No. Effects & $\begin{array}{c}\text { STC } \\
\mathrm{kWh} / \mathrm{m}^{3}\end{array}$ & No. Effects \\
\hline 200 & 66.99 & 13 & 61.2 & 14 \\
\hline 220 & 62.73 & 14 & 57.72 & 15 \\
\hline 240 & 59.17 & 15 & 54.74 & 16 \\
\hline 260 & 56 & 16 & 52.08 & 17 \\
\hline 280 & 53.29 & 17 & 49.81 & 18 \\
\hline 300 & 50.85 & 18 & 47.76 & 19 \\
\hline \multicolumn{5}{|l|}{ P bar } \\
\hline 10 & 76.7 & 11 & 69.29 & 12 \\
\hline 11 & 71.41 & 12 & 64.99 & 13 \\
\hline 12 & 67.14 & 13 & 61.31 & 14 \\
\hline 13 & 63.37 & 14 & 58.16 & 15 \\
\hline 14 & 60.11 & 15 & 55.4 & 16 \\
\hline 15 & 57.22 & 16 & 52.98 & 17 \\
\hline 16 & 54.74 & 15 & 50.87 & 18 \\
\hline \multicolumn{5}{|l|}{$Q_{D i 1} \mathrm{~L} / \mathrm{h}$} \\
\hline 3000 & 58.16 & 14 & 55.08 & 15 \\
\hline 3500 & 58.99 & 14 & 55.42 & 15 \\
\hline 4000 & 59.59 & 14 & 55.79 & 15 \\
\hline 4500 & 60.28 & 14 & 56.14 & 15 \\
\hline 5000 & 60.83 & 14 & 56.47 & 15 \\
\hline
\end{tabular}

\section{Conclusions}

CLPRO process was suggested for power generation using single and dual stage configuration. A computer model was developed to predict the performance of the DSPRO process. The effect of membrane area, DS flow rate and draw solution pressure on the performance of the DSPRO process was investigated. Simulation results revealed that the effect of the draw solution pressure on the performance of the first stage was higher than the effect of other parameters. On the other hand, the DS flow rate was the most influential parameters in the second stage. As such, the draw solution pressure needs to be optimized during the design of a DSPRO process.

Regardless the regeneration process, the dual stage CLPRO process outperformed the single stage CLPRO process, which underlined the superiority of the former system for power generation by osmotic energy. The power density of the DSPRO process was $43 \%$ more than that generated by the single stage CLPRO process. Furthermore, the simulation results showed that the MED 
system requires about $3{ }^{\circ} \mathrm{C}$ higher temperature for the regeneration of the draw solution in the dual stage CLPRO process. This thermal process would be

892 feasible as a heat engine when an affordable source of low grade heat is available. In terms of capital costs, it would be slightly higher in the case of dual stage CLPRO due to the larger membrane and heat transfer areas of the PROMED system but capital cost increase will be paid off over time due to the higher energy efficiency of the dual stage CLPRO process.

\section{Appendix 1: Equations of the MED model.}

The MED model is described elsewhere [36-37], but some equations have been particularized for this study.

The area of each evaporator $\left(A_{e f f, i}\right)$ was determined by calculating the temperature difference between the un-evaporated brine in the effect $i\left(T_{b, i}\right)$ and the vapour that comes from the preceding effect and enters in the effect $i\left(T_{v, i-1}\right)$, and the heat transfer rate provided to the effect $i\left(Q_{e f f, i}\right)$. Likewise, rate of heat transfer is equal to the change in enthalpy related to the condensation of the vapour coming from the previous effect and entering in the effect $i\left(\lambda_{v, i-1}\right)$ :

$$
Q_{\text {eff }, i}=U_{\text {eff }, i} A_{\text {eff }, i}\left(T_{v, i-1}-T_{b, i}\right)=M_{v, i} \lambda_{v, i-1}
$$

where $U_{e f f, i}$ is the total heat transfer coefficient, which is obtained by the correlation suggested in our previous work [37], and $M_{v, i}$ is the vapour mass flow rate going to the bundle tube of each effect, which consists of the total vapour generated by boiling of the brine $\left(M_{g b, i-1}\right)$, flashing of the brine $\left(M_{g f, i-1}\right)$ and flashing of the distilled water in the flash box $\left(M_{d f, i-1}\right)$, all of it minus the vapour consumed in the preheater $\left(M_{v h, i-1}\right)$, as shown in the following equation:

$$
M_{v, i}=\left(M_{g b, i-1}+M_{g f, i-1}+M_{d f, i-1}\right)-M_{v h, i-1}
$$

Each mass flow rate of the previous equation $(M)$, is determined by energy balances in the effects, the preheaters and the flash boxes.

The vapour consumed in the preheater, $M_{v h, i}$, is condensed releasing latent heat $\lambda_{v h, i}$ (at a temperature $T_{v, i}$ ) which is utilized to heat the feed water flowing through the preheaters tube bundle:

$$
M_{v h, i} \lambda_{v h, i}=M_{f} C_{p}\left(T_{p h, i}-T_{p h, i+1}\right)
$$

where $T_{p h, i}$ is the feed water temperature in the bundle tube of a preheater $i$, and $M_{f}$ is defined as the mass flow rate of feed solution sprayed in $1^{\text {st }}$ effect. 
930 In the case of preheaters, it was assumed an equal temperature difference 931 between preheaters $\left(\Delta T_{p r e h_{i} i}\right)$, which is determined from the following expression:

932

933

934

935

936

937

938

939

940

941

942

943

944

945

946

947

948

949

950

951

952

953

954

955

956

957

958

959

960

961

962

963

964

965

$\Delta T_{p r e h, i}=\frac{T_{p h, 1}-T_{p h, N p h}}{N_{p h}}$

where $N_{p h}$ is the number of preheaters, which is considered equal to $N-1$.

Additionally, mass flow rate of the vapour generated in each evaporator is obtained by the following energy balance:

$M_{g b, i} \lambda_{g b, i}=M_{v, i} \lambda_{v, i-1}+M_{d b, i} C_{p}\left(T_{d b, i}-T_{b, i}\right)$

$M_{d b, i}$ is the mass flow rate of the brine solution after flashing once it enters the effect (at a higher pressure than that one inside the effect), $\lambda_{g b, i}$ is the latent heat of vaporization at $T_{v, i}$ and $T_{d b, i}$ is the un-evaporated brine temperature after flashing. $M_{d b, i}$ was determined by the following mass balance:

$M_{d b, i}=M_{b, i-1}-M_{g f, i}$

The mass flow rate of the flashing brine was determined by an energy balance:

$$
M_{g f, i} \lambda_{g f, i}=M_{b, i-1} C_{p}\left(T_{b, i-1}-T_{d b, i}\right)
$$

where $\lambda_{g f_{, i} i}$ is the vaporization latent heat at $T_{v, i}$.

Both mass flow rates $\left(M_{g f}, M_{d b}\right)$ were considered zero in the first effect, since in this case the feed solution enters at a temperature below saturation (sub-cooled);

i.e. no vapour is produced by the flashing process.

$M_{b, i}$ is the mass flow rate of the brine that leaves each effect and enters the following one and it was determined from the following equation:

$$
M_{b, i}=M_{d b, i}-M_{g b, i}
$$

Finally, the mass flow rate of the vapour produced through flashing of the distillate in each flash box was calculated by:

$$
\begin{aligned}
M_{d f, i} \lambda_{d f, i}= & M_{v h, i-1} C_{p}\left(T_{v, i-1}-T_{v, i}\right)+M_{v, i-1} C_{p}\left(T_{v, i-1}-T_{v, i}\right)+M_{d, i-1} C_{p}\left(T_{v, i-1}\right. \\
& \left.-T_{v, i}\right)
\end{aligned}
$$

where $\lambda_{d f, i}$ is the vaporization latent heat at $T_{v, i}$ and $M_{d, i}$ is the distillate mass flow rate leaving each flash box, which was determined from the following mass balance formula: 


$$
M_{d, i}=M_{v, i}+M_{v h, i-1}+M_{d, i-1}-M_{d f, i}
$$

\section{Acknowledgements}

The authors wish to acknowledge the European Commission (DG for Research \& Innovation) for its financial support in the EU 7th Framework Program SFERA-II project (Grant Agreement n. 312643).

\section{Abbreviations:}

\begin{tabular}{|l|l|}
\hline Abbreviation & Full Meaning \\
\hline CLPRO & Closed-Loop Pressure Retarded Osmosis \\
\hline MED & Multi-Effect Distillation \\
\hline RO & Reverse Osmosis \\
\hline PRO & Pressure Retarded Osmosis \\
\hline RED & Reverse Electrodialysis \\
\hline DS & Draw Solution \\
\hline FS & Feed Solution \\
\hline CP & Concentration Polarization \\
\hline DSPRO & Dual Stage Pressure Retarded Osmosis \\
\hline SSPRO & Standard Single Stage Pressure Retarded Osmosis \\
\hline ERD & Energy Recovery Device \\
\hline TBT & Top Brine Temperature \\
\hline BPE & boiling point elevation \\
\hline RR & Recovery Ratio \\
\hline STC & Specific Thermal Consumption \\
\hline
\end{tabular}

\section{Nomenclature}

\begin{tabular}{|l|l|}
\hline Nomenclature & Full Meaning \\
\hline$Q_{p}$ & PRO permeate flow rate $\left(\mathrm{m}^{3} / \mathrm{h}\right)$ \\
\hline$\pi_{D b}$ & osmotic pressure of the bulk draw solution (bar) \\
\hline$\pi_{F b}$ & osmotic pressure of the feed draw solution (bar) \\
\hline$K$ & mass transfer coefficient $(\mathrm{m} / \mathrm{s})$ \\
\hline$A_{m}$ & PRO membrane area $\left(\mathrm{m}^{2}\right)$ \\
\hline$A_{w}$ & water permeability coefficient $\left(\mathrm{L} / \mathrm{m}^{2} \mathrm{~h}\right.$ bar) \\
\hline$\Delta P$ & hydraulic pressure difference $(\mathrm{bar})$ \\
\hline$\Delta \Pi$ & osmotic pressure gradient $(\mathrm{bar})$ \\
\hline$B$ & solute permeability coefficient $(\mathrm{m} / \mathrm{h})$ \\
\hline$K$ & solute resistivity for diffusion within porous support layer $(\mathrm{s} / \mathrm{m})$ \\
\hline$J_{w}$ & membrane flux $\left(\mathrm{L} / \mathrm{m}^{2} \mathrm{~h}\right)$ \\
\hline$T$ & feed temperature $(\mathrm{K})$ \\
\hline$m_{n}$ & molar concentration of $\mathrm{n}^{\text {th }}$ ion species \\
\hline
\end{tabular}




\begin{tabular}{|c|c|}
\hline$C_{\mathrm{Nab}}$ & bulk concentration of $\mathrm{Na}$ ion $(\mathrm{mg} / \mathrm{L})$ \\
\hline$C_{C l b}$ & bulk concentration of $\mathrm{Cl}$ ion $(\mathrm{mg} / \mathrm{L})$ \\
\hline$M w_{\mathrm{Na}}$ & molecular weight of $\mathrm{Na}(\mathrm{mg} / \mathrm{M})$ \\
\hline$M w_{C I}$ & molecular weight of $\mathrm{Cl}(\mathrm{mg} / \mathrm{M})$ \\
\hline$C_{D i}$ & inlet concentration of draw solution (mg/L) \\
\hline$C_{D o}$ & outlet concentration of draw solution $(\mathrm{mg} / \mathrm{L})$ \\
\hline$Q_{D i}$ & inlet flow rate of draw solution $(\mathrm{L} / \mathrm{h})$ \\
\hline$Q_{D_{0}}$ & outlet flow rate of draw solution (L/h) \\
\hline$C_{p}$ & permeate concentration $(\mathrm{mg} / \mathrm{L})$ \\
\hline$w$ & power density $\left(\mathrm{W} / \mathrm{m}^{2}\right)$ \\
\hline$C_{p}$ & permeate concentration $(\mathrm{mg} / \mathrm{L})$ \\
\hline$P_{w}$ & power generation $(\mathrm{kW})$ \\
\hline$R e$ & PRO recovery rate \\
\hline$Q_{F}$ & feed flow rate $(\mathrm{L} / \mathrm{h})$ \\
\hline$Q_{P}$ & permeate flow rate $(\mathrm{L} / \mathrm{h})$ \\
\hline$\Delta \pi$ & osmotic pressure gradient (bar) \\
\hline Es-ro & specific power consumption of $\mathrm{RO}\left(\mathrm{kWh} / \mathrm{m}^{3}\right)$ \\
\hline$P_{f}$ & RO feed pressure (bar) \\
\hline$P_{p}$ & RO permeate pressure (bar) \\
\hline$P_{W-R O}$ & RO power consumption (kWh) \\
\hline$\eta$ & Pump efficiency \\
\hline$Q_{\text {hpp }}$ & feed flow rate of high pressure pump $\left(\mathrm{m}^{3} / \mathrm{h}\right)$ \\
\hline$Q_{b p}$ & feed flow rate of booster pump $\left(\mathrm{m}^{3} / \mathrm{h}\right)$ \\
\hline$Q_{s p}$ & feed flow rate of supply pump $\left(\mathrm{m}^{3} / \mathrm{h}\right)$ \\
\hline$P_{\text {bpin }}$ & inlet pressure of booster pump (bar) \\
\hline$P_{\text {hpp }}$ & outlet pressure of high pressure pump (bar) \\
\hline Pthpp & pressure of feed flow to the high pressure pump (bar) \\
\hline$P_{f-s p}$ & pressure of feed flow to supply pump (bar) \\
\hline$\eta_{\text {hpp }}$ & efficiency of high pressure pump \\
\hline$\eta_{b p}$ & efficiency of booster pump \\
\hline$\eta_{s p}$ & efficiency of supply pump \\
\hline$N$ & number of effects \\
\hline$N_{p h}$ & number of preheaters \\
\hline $\boldsymbol{T}_{v, i}$ & vapor temperature generated in the i effect $\left({ }^{\circ} \mathrm{C}\right)$ \\
\hline$T_{v_{N, N}}$ & vapor temperature generated in the last effect $\left({ }^{\circ} \mathrm{C}\right)$ \\
\hline$T_{b, 1}$ & brine temperature of un-evaporated solution through MED $\left({ }^{\circ} \mathrm{C}\right)$ \\
\hline$\Delta T_{\text {eff }, i}$ & temperature difference in MED effects $\left({ }^{\circ} \mathrm{C}\right)$ \\
\hline$T_{f}$ & temperature of feed water $\left({ }^{\circ} \mathrm{C}\right)$ \\
\hline$T_{c w, i n}$ & cooling water inlet temperature $\left({ }^{\circ} \mathrm{C}\right)$ \\
\hline$T_{c w, o u t}$ & cooling water outlet temperature $\left({ }^{\circ} \mathrm{C}\right)$ \\
\hline & temperature of low pressure steam $\left({ }^{\circ} \mathrm{C}\right)$ \\
\hline$T_{p h, i}$ & feed water temperature in the bundle tube of a preheater $i$ \\
\hline$\Delta T_{\text {preh }, i}$ & temperature difference between preheaters $\left({ }^{\circ} \mathrm{C}\right)$ \\
\hline$T_{d b, i}$ & un-evaporated brine temperature after flashing $\left({ }^{\circ} \mathrm{C}\right)$ \\
\hline$A_{\text {eff }, i}$ & area of each effect $\left(\mathrm{m}^{2}\right)$ \\
\hline
\end{tabular}




\begin{tabular}{|l|l|}
\hline$U_{e f f, i}$ & total heat transfer coefficient (W \\
\hline $\boldsymbol{Q}_{e f f, i}$ & heat transfer provided to the i-effect of MED \\
\hline$M_{s}$ & flow rate of low pressure steam mass \\
\hline$M_{p r o d}$ & total distillate flow rate \\
\hline$M_{f}$ & mass flow rate of feed solution sprayed in $1^{\text {st }}$ effect \\
\hline$\lambda_{s}$ & enthalpy change related to the vapor condensation \\
\hline$\lambda_{g b, i}$ & latent heat of vaporization \\
\hline $\boldsymbol{M}_{v, i}$ & vapour mass flow rate going to the bundle tube of each effect \\
\hline$M_{g b, i-1}$ & vapour mass flow rate generated by boiling of the brine \\
\hline $\boldsymbol{M}_{g f, i-1}$ & vapour mass flow rate generated by flashing of the brine \\
\hline $\boldsymbol{M}_{d f, i-1}$ & $\begin{array}{l}\text { vapour mass flow rate generated by flashing of the distillate } \\
\text { water }\end{array}$ \\
\hline $\boldsymbol{M}_{v h, i-1}$ & vapour mass flow rate consumed in preheater \\
\hline $\boldsymbol{M}_{d b, i}$ & mass flow rate of the brine solution after flashing \\
\hline
\end{tabular}

\section{References}

[1] Jonathan Maisonneuve, Claude B. Laflamme, Pragasen Pillay, Experimental investigation of pressure retarded osmosis for renewable energy conversion: Towards increased net power, Applied Energy, V 164 (2016), 425-435

[2] Wei He, Jihong Wang, Feasibility study of energy storage by concentrating/desalinating water: Concentrated Water Energy Storage, Applied Energy, V (2017), 872-884

[3] R. Wang, C. Tang, A.G. Fane, Development of pressure retarded osmosis (PRO) membranes with high power density for osmotic power harvesting, in: Proceedings of the 3rd Osmosis Membrane Summit, Statkraft, Barcelona, 2012.

[4] Leonardo D. Banchik, Mostafa H. Sharqawy, John H. Lienhard V, Limits of power production due to finite membrane area in pressure retarded osmosis, Journal of Membrane Science, V 468 (2014), 81-89

[5] Thor Thorsen, Torleif Holt, The potential for power production from salinity gradients by pressure retarded osmosis, Journal of Membrane Science, V 335 (2009), 103-110.

[6] Eanna Farrell, Mohamed I. Hassan, Ramato A. Tufa, Arttu Tuomiranta, Ahmet H. Avci, Antonio Politano, Efrem Curcio, Hassan A. Arafat, Reverse electrodialysis powered greenhouse concept for water- and energy-self-sufficient agriculture, Applied Energy, V 187 (2017), 390-409

[7] O.A. Alvarez-Silva, A.F. Osorio, C. Winter, Practical global salinity gradient energy potential, Renewable and Sustainable Energy Reviews 60 (2016), 13871395.

[8] Gang Han, Qingchun Ge, Tai-Shung Chung, Conceptual demonstration of novel closed-loop pressure retarded osmosis process for sustainable osmotic energy generation, Applied Energy 132 (2014), 383-393.

1010

1011 [9] J. Kim, S.J. Kim, D.-K. Kim. Energy harvesting from salinity gradient by reverse electrodialysis with anodic alumina nanopores. Energy 51 (2013), 413421. 
1012 [10] Jeri L. Prante, Jeffrey A. Ruskowitz, Amy E. Childress, Andrea Achilli: RO1013 PRO desalination: An integrated low-energy approach to seawater desalination, 1014 Applied Energy, V 120 (2014), 104-114

1015 [11] Jonathan Maisonneuve, Claude B. Laflamme, Pragasen Pillay, Experimental 1016 investigation of pressure retarded osmosis for renewable energy conversion: Towards increased net power, Applied Energy, V 164 (2016), 425-435

1018 [12] A. Altaee, G. Millar, G. Zaragoza, Integration and Optimization of Pressure 1019 Retarded Osmosis with Reverse Osmosis for Power Generation and High

\section{Efficiency Desalination, Energy, 103 (2016), 110-118.}

[13] Sidney Loeb, One hundred and thirty benign and renewable megawatts from Great Salt Lake? The possibilities of hydroelectric power by pressure-retarded osmosis, Desalination, V 141 (2001), 85-91

[14] Sidney Loeb, Energy production at the Dead Sea by pressure-retarded osmosis: challenge or chimera? Desalination, V 120 (1998), 247-262

[15] Keiichiro Saito, Morihiro Irie, Shintaro Zaitsu, Hideyuki Sakai, Hidechito Hayashi, Akihiko Tanioka, Power generation with salinity gradient by pressure retarded osmosis using concentrated brine from SWRO system and treated sewage as pure water, Desalination and Water Treatment, V 41 (2012), 114-121. [16] A. Efraty, Pressure retarded osmosis in closed circuit: a new technology for clean power generation without need of energy recovery, Desalination and Water Treatment 51:40-42 (2013), 7420-7430.

[17] M. Reali, Closed cycle osmotic power-plants for electric-power production Energy, 5 (1980), 325-329

[18] S. Loeb, F. Van Hessen, D. Shahaf, Production of energy from concentrated brines by pressure-retarded osmosis: II. Experimental results and projected energy costs, J. Membr. Sci., V 1(1976), 249-269.

[19] Gang Han, Sui Zhang , Xue Li, Tai-Shung Chung, High performance thin film composite pressure retarded osmosis (PRO) membranes for renewable salinitygradient energy generation, Journal of Membrane Science, V 440 (2013),108121.

[20] R Wang, L Shi, Q She, C Tang, AG Fane, Thin-film composite hollow fiber membranes for pressure retarded osmosis (PRO) process with high power density, Journal of Membrane Science 389 (2012), 25-33.

[21] Karen Gerstandt, K.-V. Peinemann, Stein Erik Skilhagen, Thor Thorsen, Torleif Holt, Membrane processes in energy supply for an osmotic power plant, Desalination, V 224 (2008), 64-70

[22] A. Achilli, T.Y. Cath, A.E. Childress, Power generation with pressure retarded osmosis: An experimental and theoretical investigation, Journal of Membrane Science, 343 (2009) 42-52..

[23] Jeffrey R. McCutcheon, Menachem Elimelech, Influence of concentrative and dilutive internal concentration polarization on flux behavior in forward osmosis, Journal of Membrane Science, Vo 284 (2006), 237-247.

[24] R.L. McGinnis, J.R. McCutcheon, M. Elimelech, A novel ammonia-carbon dioxide osmotic heat engine for power generation, Journal of Membrane Science, V 305, (2007) 13-19. 
[25] Ali Altaee, Adel Sharif, Pressure retarded osmosis: advancement in the process applications for power generation and desalination, Desalination, V 356 1059 (2015), 31-46

1060 [26] Daniel D. Anastasio, Jason T. Arena, Emily A. Cole, Jeffrey R. McCutcheon, 1061 Impact of temperature on power density in closed-loop pressure retarded osmosis for grid storage, Journal of Membrane Science 479 (2015), 240-245. [27] A. Altaee, A. Sharif, G. Zaragoza, N. Hilal, Dual stage PRO process for power generation from different feed resources, Desalination, V 352 (2014), 118127

[28] Endre Nagy, A general, resistance-in-series, salt-and water flux models for forward osmosis and pressure-retarded osmosis for energy generation, Journal of Membrane Science, V 460 (2014), 71-81.

[29] Wei He, Yang Wang, Mohammad Hasan Shaheed, Enhanced energy generation and membrane performance by two-stage pressure retarded osmosis (PRO), Desalination, V 359 (2015), 186-199

[30] Ata Hassan, Fully integrated NF-thermal seawater desalination process and equipment, US Patents No 2006/0157410 A1, July 20, 2006

[31] Ali Altaee, Graeme J. Millar, Guillermo Zaragoza, Adel Sharif, Energy Efficiency of RO and FO-RO system for High Salinity Seawater Treatment, Clean Technologies and Environmental Policy, DOI 10.1007/s10098-016-1190-3. [32] Ali Altaee, Ahmad Fauzi Ismail, Adel Sharif \& Guillermo Zaragoza, Dual stage PRO process: impact of the membrane materials of the process performance, Desalination and Water Treatment, V 57 (2016), 6172-6183

[33] Gemma Raluy, Luis Serra, Javier Uche, Life cycle assessment of MSF, MED and RO desalination technologies, Energy, V 31 (2006), 2361-2372

[34] O.J. Morin, Design and operating comparison of MSF and MED systems, Desalination, V 93 (1993), 69-109

[35] P. Palenzuela, D. Alarcón, G. Zaragoza, J. Blanco and M. Ibarra, Parametric equations for the variables of a steady-state model of a multi-effect desalination plant. Desalination and Water Treatment, 51:4-6 (2013), 1229-1241.

[36] P. Palenzuela, A.S. Hassan, G. Zaragoza, D.C. Alarcón-Padilla. Steady state model for multi-effect distilllation case study: Plataforma Solar de Almería MED pilot plant. Desalination 337 (2014) 31-42.

[37] Hanmin Zhang, Shiying Cheng, Fenglin Yang, Use of a spacer to mitigate concentration polarization during forward osmosis process, Desalination, V 347 (2014), 112-119

[38] Huayong Luo, Qin Wang, Tian C. Zhang, Tao Tao, Aijiao Zhou, Lin Chen, Xufeng Bie, A review on the recovery methods of draw solutes in forward osmosis, Journal of Water Process Engineering, V 4 (2014), 212-223

[39] Palenzuela, P., G. Zaragoza, D.C. Alarcón-Padilla. Characterisation of the coupling of multi-effect distillation plants to concentrating solar power plants. Energy, 82, 986-995, 2015.

[40] B. Peñate, J.A. de la Fuente, M. Barreto, Operation of the RO Kinetic energy recovery system: Description and real experiences. Desalination 252 (2010) 179185 